US Army Corps

of Engineers ${ }_{\circledast}$

Engineer Research and

Development Center

\title{
Estimating Bridge Reliability by Using Bayesian Networks
}

Andrew B. Groeneveld, Stephanie G. Wood, Edgardo Ruiz, and

February 2021 Jeffery M. Roberts 
The U.S. Army Engineer Research and Development Center (ERDC) solves the nation's toughest engineering and environmental challenges. ERDC develops innovative solutions in civil and military engineering, geospatial sciences, water resources, and environmental sciences for the Army, the Department of Defense, civilian agencies, and our nation's public good. Find out more at www.erdc.usace.army.mil.

To search for other technical reports published by ERDC, visit the ERDC online library at https://erdclibrary.on.worldcat.org/discovery. 


\section{Estimating Bridge Reliability by Using Bayesian Networks}

Andrew B. Groeneveld, Stephanie G. Wood, and Edgardo Ruiz

Geotechnical and Structures Laboratory

U.S. Army Engineer Research and Development Center

3909 Halls Ferry Road

Vicksburg, MS 39180-6199

Jeffery M. Roberts

Portland District

U.S. Army Corps of Engineers

З3з SW First Avenue

Portland, OR 97204-3440

Final report

Approved for public release; distribution is unlimited.

Prepared for U.S. Army Corps of Engineers

Washington, DC 20314-1000

Under Project 476923, “Navigation Systems”

Prepared for Headquarters, Installation Management Command Fort Sam Houston, TX 78234-1223

Under Project 154349, “Army Dams and Transportation Infrastructure Program” 


\section{Abstract}

As part of an inspection, bridge inspectors assign condition ratings to the main components of a bridge's structural system and identify any defects that they observe. Condition ratings are necessarily somewhat subjective, as they are influenced by the experience of the inspectors. In the current work, procedures were developed for making inferences on the reliability of reinforced concrete girders with defects at both the cross section and the girder level. The Bayesian network (BN) tools constructed in this work use simple structural mechanics to model the capacity of girders. By using expert elicitation, defects observed during inspection are correlated with underlying deterioration mechanisms. By linking these deterioration mechanisms with reductions in mechanical properties, inferences on the reliability of a bridge can be made based on visual observation of defects. With more development, this $\mathrm{BN}$ tool can be used to compare conditions of bridges relative to one another and aid in the prioritization of repairs. However, an extensive survey of bridges affected by deterioration mechanisms is needed to confidently establish valid relationships between deterioration severity and mechanical properties.

DISCLAIMER: The contents of this report are not to be used for advertising, publication, or promotional purposes. Citation of trade names does not constitute an official endorsement or approval of the use of such commercial products. All product names and trademarks cited are the property of their respective owners. The findings of this report are not to be construed as an official Department of the Army position unless so designated by other authorized documents. 


\section{Contents}

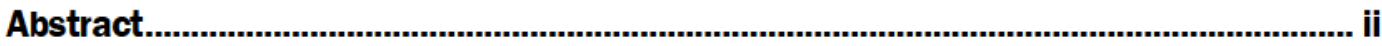

Figures and Tables................................................................................................................

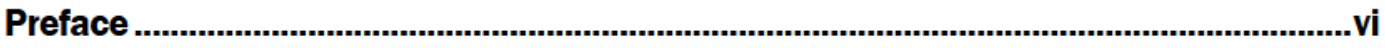

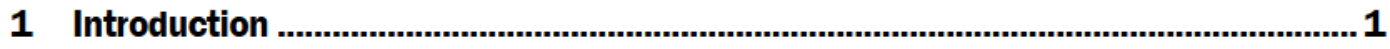

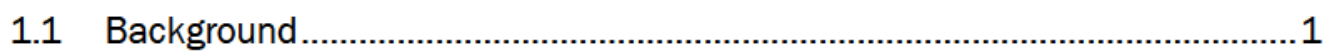

1.2 Objective of current work .......................................................................

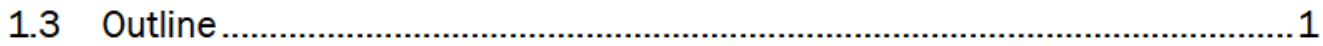

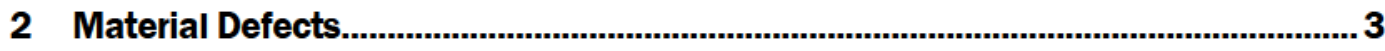

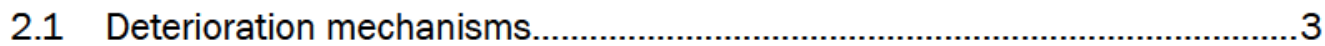

2.2 Effects on mechanical properties................................................................

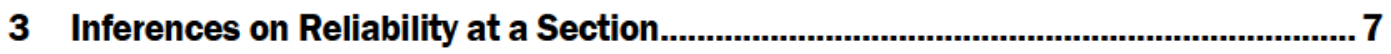

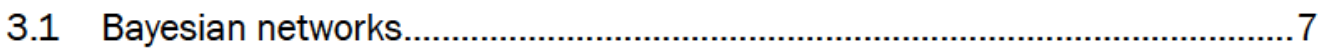

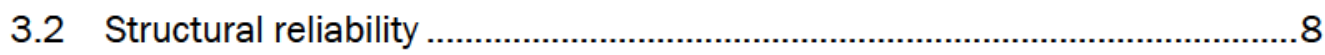

3.3 Establishing conditional probability tables for defects ..................................

3.4 Reinforced concrete girder with defects ....................................................11

4 Programmatic Generation of Bayesian Networks ..............................................16

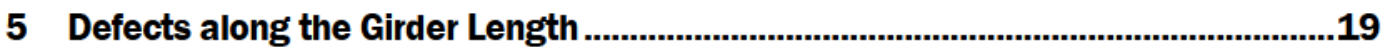

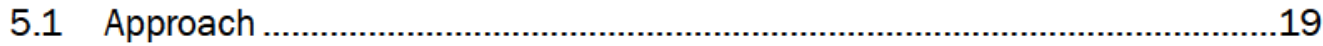

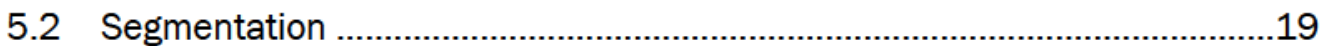

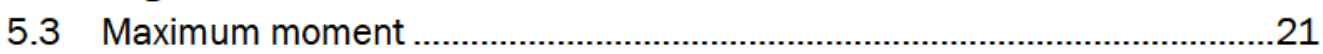

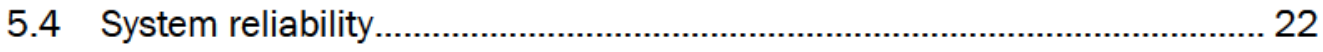

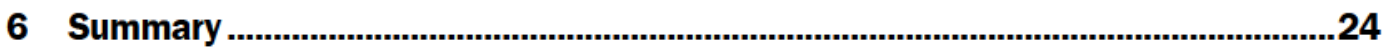

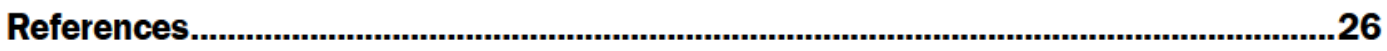

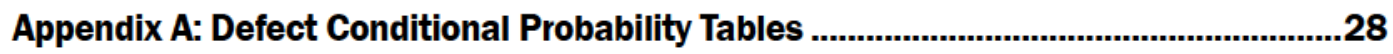

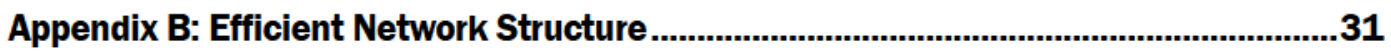

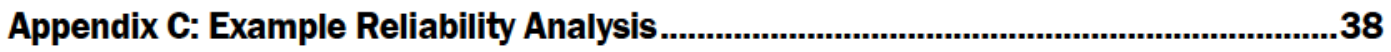

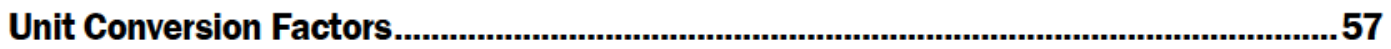

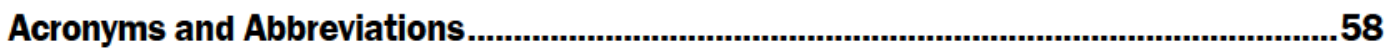

Report Documentation Page 


\section{Figures and Tables}

\section{Figures}

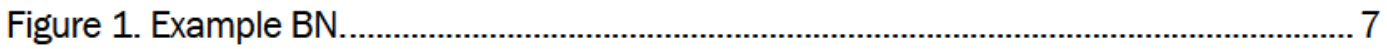

Figure 2. Full BN for analysis of an RC girder at a single section.....................................12

Figure 3. Example of Bridge Reliability program...............................................................17

Figure 4. Example of Girder Condition program. ............................................................18

Figure 5. Illustration of segmentation process for a girder. ...............................................20

Figure 6. Effect of segmentation on computed probability of failure. ................................23

Figure B1. Naïve BN for RC moment capacity. .................................................................32

Figure $\mathrm{B} 2$. BN for $\mathrm{RC}$ moment capacity using reduced variables for rebar

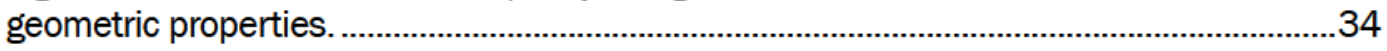

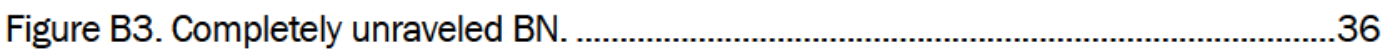

Figure C1. New Model dialog. .......................................................................................38

Figure C2. Default reinforced concrete girder model created from template. .....................40

Figure C3. Model with distribution details hidden............................................................... 41

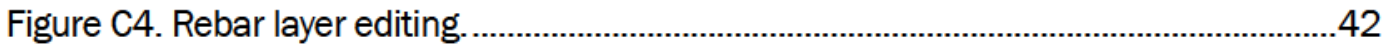

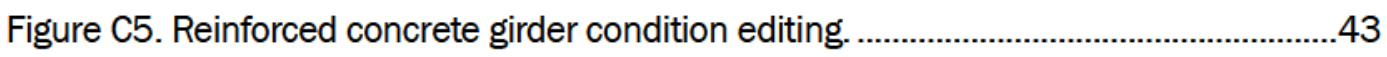

Figure C6. Attempting to run an analysis with an unsaved file.............................................43

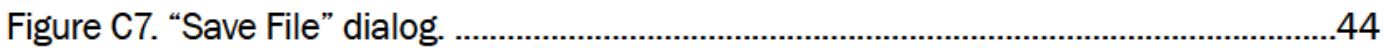

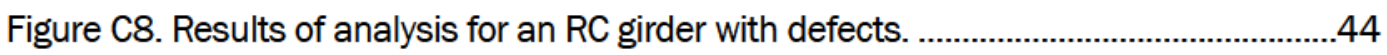

Figure C9. Results of analysis for an RC girder without defects.......................................45

Figure C10. Girder Condition program showing “Finding Entry” dialog box. ........................46

Figure C11. Defect start and stop locations. .................................................................46

Figure C12. Defects for example analysis. ..................................................................... 47

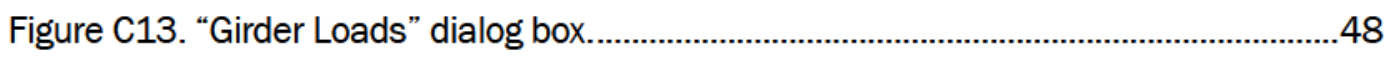

Figure $\mathrm{C} 14$. Select the RC girder model for the example analysis....................................50

Figure C15. Analysis summary information. ..................................................................50

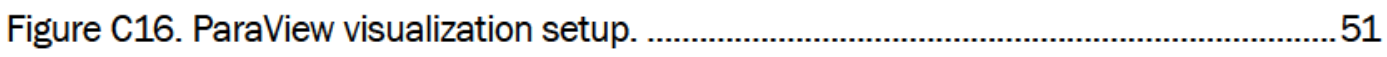

Figure C17. Variables available to visualize ....................................................................52

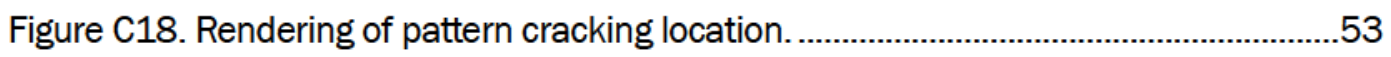

Figure C19. Rendering of spalling location and severity. .................................................54

Figure C20. Rendering of efflorescence location and severity..........................................54

Figure C21. Rendering of probability of failure for girder segments..................................55

Figure C22. Rendering of probability of moderate ASR for girder segments. ......................56 


\section{Tables}

Table 1. Sample of literature results for mechanical properties of FT-affected concrete in laboratory studies.

Table 2. List of defects associated with common concrete deterioration

mechanisms. 10

Table 3. Example of probability table for ASR-induced cracking in concrete. .11

Table 4. Parameters of random variables. .13

Table 5. Concrete compressive strength reductions based on deterioration. .14

Table A1. CPT for cracking severity. .28

Table A2. CPT for delamination severity. 29

Table A3. CPT for efflorescence severity. .29

Table A4. CPT for exposed rebar severity. .29

Table A5. CPT for pattern cracking occurrence. .29

Table A6. CPT for rust staining severity. .30

Table A7. CPT for spalling severity. .30

Table B1. CPT size for completely unraveled BN example. 


\section{Preface}

This study was conducted for the U.S. Army Corps of Engineers under Project 476923, "Navigation Systems." The program manager was Mr. Charles E. Wiggins, Technical Director for Navigation, U.S. Army Engineer Research and Development Center, Coastal and Hydraulics Laboratory (ERDC-CHL). The technical monitor was Mr. Edgardo Ruiz, Research Civil Engineer, U.S. Army Engineer Research and Development Center, Geotechnical and Structures Laboratory (ERDC-GSL).

The Army Dams and Transportation Infrastructure Program (ADTIP) from the Installation Management Command (IMCOM) provided supplemental funding for this effort under Project 154349, "Army Dams and Transportation Infrastructure Program.” The program manager was Mr. Gerardo I. Velázquez, Research Structural Engineer, ERDC-GSL.

The work was led by the Structural Engineering Branch (StEB) of the Geosciences and Structures Division (GSD), ERDC-GSL, with contributions from the Concrete and Materials Branch (CMB) of the Engineering Systems and Materials Division (ESMD), ERDC-GSL, and the USACE Portland District (NWP). At the time of publication, Ms. Mariely Mejías-Santiago was Chief, StEB, and Mr. James L. Davis was Chief, GSD. The Deputy Director of ERDC-GSL was Mr. Charles W. Ertle II, and the Director was Mr. Bartley P. Durst.

COL Teresa A. Schlosser was the Commander of ERDC, and Dr. David W. Pittman was the Director. 


\section{Introduction}

\subsection{Background}

As part of an inspection, bridge inspectors assign condition ratings to and identify any observed defects in the bridge's three main parts: the deck, the superstructure, and the substructure. The inspection team leader is relied on to consider the severity of the defects and their effect on component performance when assigning condition ratings. However, the judgment and past experience of the inspection team plays a large role in determining the ratings. Thus, ratings have an element of subjectivity, and ratings for the same structure can vary between different inspection teams.

There is a need for a quantitative way to interpret inspection findings and to determine the impact of any defects on bridge reliability. This work explores the use of Bayesian networks (BNs) for making inferences on bridge reliability based on observed defects. A BN is a type of probabilistic graphical model that expresses the causal relationships between variables. $\mathrm{BNs}$ can be used to model knowledge subject to uncertainty and to make inferences on the most likely state of variables in the model, given information or observations about other variables. The BNs constructed in this work use simple structural mechanics to model the capacity of girders and expert knowledge to connect defects, which can be observed during an inspection, to underlying deterioration mechanisms, which cannot be easily observed and must be inferred. By linking these deterioration mechanisms with reductions in mechanical properties, inferences on the reliability of a bridge can be made based on visual observation of defects.

\subsection{Objective of current work}

The objective of this work is to develop a process for using BNs to make inferences on reinforced concrete (RC) bridge reliability, incorporating findings about defects.

\subsection{Outline}

The remainder of this report is organized as follows. The most common material defects affecting concrete and their effects on mechanical properties are described in Chapter 2. The basic theory used to make inferences on reliability is introduced in Chapter 3 in the context of 
analyzing the flexural capacity of an RC girder section with defects. For addressing practical problems when a bridge girder has multiple defects at different locations, an automated means of performing multiple analyses is needed. The basic framework for this automation is presented in Chapter 4, and details of its implementation are given in Chapter 5. Chapter 6 summarizes the key conclusions from this work and identifies possible areas for future work. 


\section{Material Defects}

This chapter provides an overview of material defects specific to RC bridges. Section 2.1 lists the major deterioration mechanisms that cause the defects, and Section 2.2 describes how these defects affect mechanical properties.

\subsection{Deterioration mechanisms}

Defects in hardened concrete are linked to either damage or deterioration. Damage is the result of an external force, such as impact or overloading, and deterioration is caused by internal phenomena. Damage-induced defects listed in the American Association of State Highway and Transportation Officials (AASHTO)'s Manual for Bridge Element Inspection (MBEI; 2013) are largely self-explanatory and unrelated to concrete deterioration. They include abrasion/wear, distortion, settlement, scour, and damage. This study deals with the less obvious deterioration mechanisms and their consequential, observable defects. The most common concrete deterioration mechanisms include corrosion of internal steel reinforcement, freeze-thaw (FT) cycling, and alkali-silica reaction (ASR).

Corrosion of internal reinforcement is caused by the ingress of carbon dioxide and chlorides into the concrete and down to the depth of the reinforcement. The resulting rust occupies more volume than the steel and exerts tensile stresses on the concrete, resulting in cracking. In concrete bridges, the chlorides are commonly supplied by the application of deicing salts. Surface symptoms of corrosion include rust staining, cracking, spalling, delamination, and exposed rebar.

FT cycling deterioration is caused when water inside the concrete pores cyclically freezes and thaws. As the water freezes, it exerts pressure inside the concrete pores and cavities. When this pressure exceeds the tensile strength of the concrete, the concrete cracks. Concretes placed prior to 1940, before the use of air-entraining admixtures, have a higher risk for FT deterioration. Additionally, concretes located in areas where nightly temperatures fall below freezing while daily temperatures rise above freezing are susceptible to this type of deterioration, particularly if lacking air entrainment and exposed to direct sunlight where cycles may be more severe. The most common manifestations of FT deterioration include efflorescence, cracking, spalling, and delamination. 
ASR is a chemical reaction between the constituents of the concrete. Alkali hydroxides present in the concrete pore solution attack reactive forms of silica contained in some aggregates. In the presence of moisture, the product of this reaction, called ASR gel, swells and causes expansion and cracking of the concrete. The alkali hydroxides are typically supplied by the portland cement, which has necessitated limits on the cement alkalinity for many projects, but may also be contributed by supplementary cementitious materials, de-icing salts, or the aggregates themselves. Surface evidence of ASR includes pattern cracking, other cracking, efflorescence, and spalling.

\subsection{Effects on mechanical properties}

If unmitigated, these deterioration mechanisms eventually become evident on the concrete surface and result in reductions in the mechanical properties. Concrete stiffness, or the elastic modulus, is the most sensitive property to the deterioration, but compressive strength and tensile strength may also be affected.

No previous work has established correlations between rated visual inspections of bridges and the reductions of the concrete mechanical properties due to deterioration. Much of the existing literature involves small-scale laboratory studies in which the deterioration and subsequent symptoms are made rapidly severe and cannot be used to quantitatively predict deterioration of and effects on full-scale members. Therefore, relationships between deterioration severity and reductions in mechanical properties are based on expert elicitation, inferring threshold values from the literature and case studies. The following paragraphs are intended to serve as high-level summaries of the variable results taken from previous work rather than an extensive literature review.

Corrosion of internal reinforcement can cause debonding of the steel from the concrete, resulting in spalling and delamination of the concrete cover. The main concern in a reinforced concrete member affected by corrosion is the loss of the tensile and flexural strengths due to rebar section loss. That is to say that the mechanical properties of the concrete are not as affected as the mechanical properties of the steel. Unless the spalling or delamination is severe enough to expose the rebar, estimates of the remaining mechanical capacity of the steel remain nearly impossible to determine by using only visual observation. 
Many studies on the relationship between FT deterioration and mechanical properties have been conducted on small-scale laboratory specimens subjected to FT cycles in a temperature-controlled chamber (Ji et al. 2008; Hanjari et al. 2011; Shang et al. 2014; Qin et al. 2016). Remaining capacities for mechanical properties from some of those studies are provided in Table 1. This sample of results from the literature highlights the variability and difficulty in defining conclusive ranges for these values. Contributing to that difficulty are the lack of visual ratings for the specimens and the inability to correlate the smallscale results with the behavior of large-scale structural members in the field.

Table 1. Sample of literature results for mechanical properties of FT-affected concrete in laboratory studies.

\begin{tabular}{|c|c|c|c|c|c|}
\hline \multirow[b]{2}{*}{ Study } & \multirow[b]{2}{*}{$\begin{array}{l}\text { Specimen } \\
\text { Size and } \\
\text { Type }\end{array}$} & \multirow[b]{2}{*}{$\begin{array}{c}\text { Number of } \\
\text { Cycles }\end{array}$} & \multicolumn{3}{|c|}{ Remaining Capacity (\%) } \\
\hline & & & $\begin{array}{l}\text { Compressive } \\
\text { Strength }\end{array}$ & $\begin{array}{l}\text { Splitting } \\
\text { Tensile } \\
\text { Strength }\end{array}$ & $\begin{array}{l}\text { Modulus of } \\
\text { Elasticity }\end{array}$ \\
\hline \multirow{3}{*}{$\begin{array}{l}\text { Ji et al. } \\
2008\end{array}$} & \multirow{3}{*}{$\begin{array}{l}150-\mathrm{mm} \\
\text { cubes }\end{array}$} & 15 & 84 & 92 & $74-81$ \\
\hline & & 30 & 74 & 84 & $47-53$ \\
\hline & & 50 & 65 & 68 & $28-38$ \\
\hline \multirow{4}{*}{$\begin{array}{l}\text { Shang et al. } \\
2014\end{array}$} & \multirow{4}{*}{$\begin{array}{l}100-\mathrm{mm} x \\
100-\mathrm{mm} x \\
200-\mathrm{mm} \\
\text { prisms }\end{array}$} & 50 & $96-100$ & - & - \\
\hline & & 100 & $92-99$ & - & - \\
\hline & & 200 & $78-100$ & - & - \\
\hline & & 400 & 54-77 & - & - \\
\hline \multirow{5}{*}{$\begin{array}{l}\text { Qin et al. } \\
2016\end{array}$} & \multirow{5}{*}{$\begin{array}{l}100-\mathrm{mm} \\
\text { cubes }\end{array}$} & 25 & 99 & - & 100 \\
\hline & & 50 & 96 & - & 99 \\
\hline & & 100 & 91 & - & 98 \\
\hline & & 200 & 78 & - & 94 \\
\hline & & 325 & 44 & - & 75 \\
\hline
\end{tabular}

The same inconsistencies among results of laboratory FT studies exist with laboratory ASR studies. Because ASR gel causes dimensional expansion of the affected concrete, the linear expansion of a specimen is used as the indicator of deterioration severity, and relationships are established between expansion levels and measured mechanical properties (Swamy and Al-Asali 1988; Smaoui et al. 2005; Giaccio et al. 2008; Liu et al. 2012). The amount an ASR-affected concrete specimen will expand depends on 
multiple variables including aggregate mineralogy, pore solution alkalinity, available moisture, conditioning temperature, and other factors. Like the FT studies, the ASR studies do not contain visual ratings, and results on small-scale specimens do not scale up to capture the behavior of large-scale structural members in the field.

In addition to the literature on laboratory studies, case studies and previous experience involving other types of concrete structures were used to estimate the remaining mechanical property capacities in the BN. One report produced by the U.S. Army Corps of Engineers Waterways Experiment Station details the evaluation of navigation lock walls affected by FT cycling, ASR, or a combination of the two deterioration mechanisms (McDonald 1987). Compressive strength and modulus of elasticity were measured on extracted cores from many of the structures in the report. The data show remaining compressive strength and elastic modulus capacities as low as 70 and $45 \%$, respectively, near the surface of the deteriorated concrete. For the cores taken from the same structure at the same depths, differences between reductions in compressive strength and elastic modulus were as high as $52 \%$, emphasizing the higher sensitivity of elastic modulus to concrete deterioration. For instance, one core had retained $95 \%$ of its original compressive strength but only $45 \%$ of its original elastic modulus. Although no visual ratings were applied, photos of deterioration are provided in the report. 


\section{Inferences on Reliability at a Section}

This chapter describes the underlying theory for analyzing the reliability of a girder at a section. Sections 3.1 and 3.2 give some brief background on BNs and structural reliability, respectively. Section 3.3 describes how conditional probabilities for material defects were established. Finally, section 3.4 presents a $\mathrm{BN}$ for making inferences on the reliability of a reinforced concrete girder section with defects.

\subsection{Bayesian networks}

A BN is a type of probabilistic graphical model that expresses the structure of interactions between variables and can be used to model knowledge subject to uncertainty (Heckerman and Wellman 1995; Pradhan et al. 1996). The BN takes the form of a directed acyclic graph, where nodes represent variables and links (or edges) represent causal relationships between variables. The graph is directed because the links represent causality, with edges running to a child node from one or more parent nodes. The graph is also acyclic, as circular dependencies between variables would be nonsensical. The relationships between variables are encoded in conditional probability tables (CPTs), which give the probability of each of a node's states given the states of its parent node(s). A simple example of a $\mathrm{BN}$ is shown in Figure 1. Node $E$ is dependent on three nodes $(A, B$, and $C)$, and node $D$ is dependent on one node $(A)$.

Figure 1. Example BN.

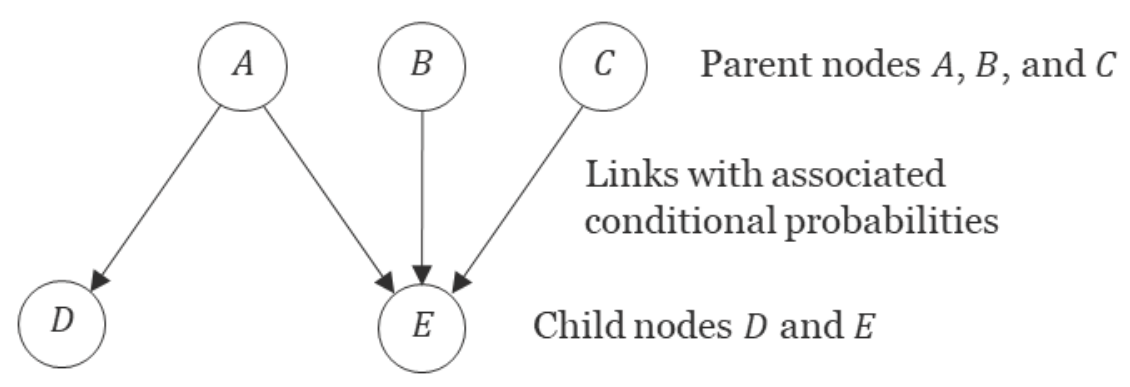

A key concept in the use of BNs is Bayes' theorem, which deals with conditional probabilities. It can be viewed in terms of a hypothesis, $\theta$, which is formed at some initial time and has some probability of being true (often called the prior probability). When new data, $x$, are obtained, they can be used to update the prior probability based on the additional information that $x$ provides about $\theta$. This is expressed as 


$$
P(\theta \mid x)=\frac{P(x \mid \theta) P(\theta)}{P(x)}
$$

where

$$
\begin{aligned}
P(\theta)= & \text { the probability of the hypothesis' being true before the data are } \\
& \text { known (prior probability) } \\
P(\theta \mid x)= & \text { the probability of the hypothesis' being true, given the new } \\
& \text { data (posterior probability) } \\
P(x \mid \theta)= & \text { the probability of the data's being observed, given that the } \\
& \text { hypothesis is true (likelihood) } \\
P(x)= & \text { the probability of the data's being observed under any } \\
& \text { circumstances (essentially a scaling factor). }
\end{aligned}
$$

Bayesian inference is the process of using new data to update prior beliefs. Because this is a probabilistic approach, Bayesian inference will not necessarily result in the correct conclusion. However, it will give the probabilities of possible conclusions, and the most likely conclusion can be selected.

\subsection{Structural reliability}

The reliability of a structure is the probability of the structure's not failing. That is, if the probability of failure is $P_{\mathrm{f}}$, then the reliability is $1-P_{\mathrm{f}}$. Thus, a definition of failure is needed to determine the reliability. Here, failure is defined as not performing as intended; specifically, having insufficient capacity to carry the applied loads. The performance (or limit) function, $g$, is defined as

$$
g(R, Q)=R-Q
$$

where

$$
\begin{aligned}
& R=\text { resistance (or capacity) } \\
& Q=\text { load effect (or demand) }
\end{aligned}
$$

With this definition, $g>0$ when the resistance exceeds the load effect, $g=$ 0 when the resistance is exactly equal to the load effect, and $g<0$ when the resistance is insufficient to support the load effect (i.e., failure). The probability of failure, $P_{\mathrm{f}}$, is then 


$$
P_{\mathrm{f}}=P(g<0) \text {. }
$$

For a normally distributed limit state function, the reliability index, $\beta$, is defined as $\mu_{g} / \sigma_{g}$, where $\mu_{g}$ and $\sigma_{g}$ are the mean and standard deviation of $g$, respectively. The reliability index represents the number of standard deviations that separate the mean value of $g$ from its value at the initiation of failure $(g=0)$. The reliability index can be approximated in a number of ways (Nowak and Collins 2012). The first order, second moment (FOSM) method uses a linear Taylor series expansion of the limit state function, $g\left(x_{1}, x_{2}, \ldots, x_{n}\right)$, about the mean values of its arguments $x_{i}$. Assuming that the variables are uncorrelated,

$$
\beta=\frac{\left.g\right|_{\boldsymbol{x}=\boldsymbol{\mu}}}{\sqrt{\sum_{i=1}^{n}\left(\left.\frac{\partial g}{\partial x_{i}}\right|_{\boldsymbol{x}=\boldsymbol{\mu}} \sigma_{i}\right)^{2}}}
$$

where the notation $\left.\cdot\right|_{x=\mu}$ has been used to indicate evaluation at the mean values of the $x_{i}$. If all variables are normally distributed, then the expression further simplifies to

$$
\beta=-\Phi^{-1}\left(P_{\mathrm{f}}\right)
$$

where $\Phi^{-1}$ is the inverse of the standard normal cumulative distribution function and $P_{\mathrm{f}}$ is defined according to equation (3).

The BN tools developed in the current project provide inferences on probability of failure [equation (3)] as their primary output, with the approximate reliability index [equation (5)] given for comparison.

\subsection{Establishing conditional probability tables for defects}

An observable defect can be due to a variety of causes. For example, cracking may be caused by drying shrinkage during concrete curing, overloading of the member, deterioration mechanisms, or other causes. Cracks from drying shrinkage, although aesthetically unpleasant, are largely harmless; but cracks caused by underlying deterioration mean 
that the condition of the concrete will likely continue to worsen, producing more cracking and other symptoms.

To better estimate the remaining capacity of a concrete member, it is important to have an idea of the cause(s) for the observed defects. For this reason, the CPTs in this study were constructed by using a tiered approach. The most common defects associated with each of the three deterioration mechanisms were listed and centered on those provided in the MBEI with some deviation and one addition. These are provided in Table 2.

Determination of the severity of each defect is based on guidance provided in the $M B E I$, and the severity ranges from 1 (good) to 4 (severe). The Federal Highway Administration provides a descriptive and visual guide for assessing the condition states of ASR-induced defects in transportation infrastructure, with the $M B E I$ serving as the basis for evaluation (Thomas et al. 2012). There are no similar documents for defects related to corrosion and FT cycling with regard to bridge inspections.

Table 2. List of defects associated with common concrete deterioration mechanisms.

\begin{tabular}{|c|c|c|c|}
\hline \multirow[b]{2}{*}{ Defect } & \multicolumn{3}{|c|}{ Deterioration Mechanism } \\
\hline & Corrosion & FT Cycling & ASR \\
\hline Cracking & $x$ & $x$ & $x$ \\
\hline Spalling & $x$ & $x$ & $x$ \\
\hline Delamination & $x$ & $x$ & \\
\hline Efflorescence & & $x$ & $x$ \\
\hline Rust Staining & $x$ & & \\
\hline Exposed Rebar & $x$ & & \\
\hline Map Cracking & & & $x$ \\
\hline
\end{tabular}

Tables were constructed in the $\mathrm{BN}$ for each defect, expressing the probability of that defect's being indicative of a particular deterioration mechanism at each of three levels of severity. An example table for ASR-induced cracking is provided in Table 3. Probabilities range from 1 to $100 \%$ and were based on expert elicitation using the following statement: Given the condition state of the defect (i.e., 1, 2, 3, or 4), then the probability distribution of the severity of the underlying deterioration mechanism (i.e., low, moderate, or severe) is inferred. For 
instance, if the condition state of the cracking is 2 , then the probability that the severity of the ASR is moderate is $35 \%$.

Table 3. Example of probability table for ASR-induced cracking in concrete.

\begin{tabular}{|l|l|l|l|l|}
\hline \multirow{2}{*}{ Severity of ASR } & \multicolumn{4}{|c|}{ Probability Based on Condition State of Cracking (\%) } \\
\cline { 2 - 6 } & $\begin{array}{c}\text { Condition State } \\
\mathbf{1}\end{array}$ & $\begin{array}{c}\text { Condition State } \\
\mathbf{2}\end{array}$ & $\begin{array}{c}\text { Condition State } \\
\mathbf{3}\end{array}$ & $\begin{array}{c}\text { Condition State } \\
\mathbf{4}\end{array}$ \\
\hline Low & 80 & 10 & 5 & 5 \\
\hline Moderate & 25 & 35 & 30 & 10 \\
\hline Severe & 3 & 15 & 42 & 40 \\
\hline
\end{tabular}

The total probability that a particular deterioration mechanism is the underlying cause for the observed defects is based on combinations of those defects and their severities. In some cases, the concrete may be affected by more than one deterioration mechanism, and this is taken into account in the network.

The CPT files for the BN are saved in plaintext format to allow easy updating. Complete CPTs are presented in Appendix A.

\subsection{Reinforced concrete girder with defects}

This section describes a $\mathrm{BN}$ for inferences on $\mathrm{RC}$ girder reliability accounting for observed defects. This extends the BN from previous work (Roberts et al. 2019), which provided reliability estimates for girders under uncertainty about material properties, loading, and other parameters, but did not account for deterioration. Roberts et al. (2019) considered RC, prestressed concrete, and steel girders. Their analysis examined the capacity and moment demand at a section along the girder that was chosen as the location of the maximum moment.

The current work focuses on RC girders with defects. A rectangular cross section is assumed, and compression reinforcement (if any is present in the section) is neglected. It is also assumed that the controlling failure mode of the girder is the strength limit state for flexure. Model development and exploration were performed by using Netica 6.04 (Norsys 2017). Initially, the BN contained nodes for the area and centroid position of each rebar layer. This allowed fine-grained control of the uncertainty for the individual layers but resulted in excessive memory and computation time requirements. Therefore, the treatment of rebar 
properties was changed as described in Appendix B. The user is still able to enter the area and centroid position for as many rebar layers as are needed. However, the program now approximates the distribution for the rebar area and first moment of area of the rebar. This greatly reduces the number of calculations required for performing inference on the BN.

The final BN, which includes this performance improvement as well as the effects of deterioration on concrete compressive strength, is shown in Figure 2. The user supplies girder properties as nominal values, which are represented in the BN by normally distributed random variables with the parameters listed in Table 4 . The bias, $\lambda$, and coefficient of variation, COV, are defined as

$$
\begin{gathered}
\lambda=\frac{\mu}{x^{\prime}} \\
\operatorname{COV}=\frac{\sigma}{\mu},
\end{gathered}
$$

where

$$
\begin{aligned}
\mu & =\text { mean value } \\
x & =\text { nominal value } \\
\sigma & =\text { standard deviation. }
\end{aligned}
$$

Figure 2. Full $\mathrm{BN}$ for analysis of an $\mathrm{RC}$ girder at a single section.

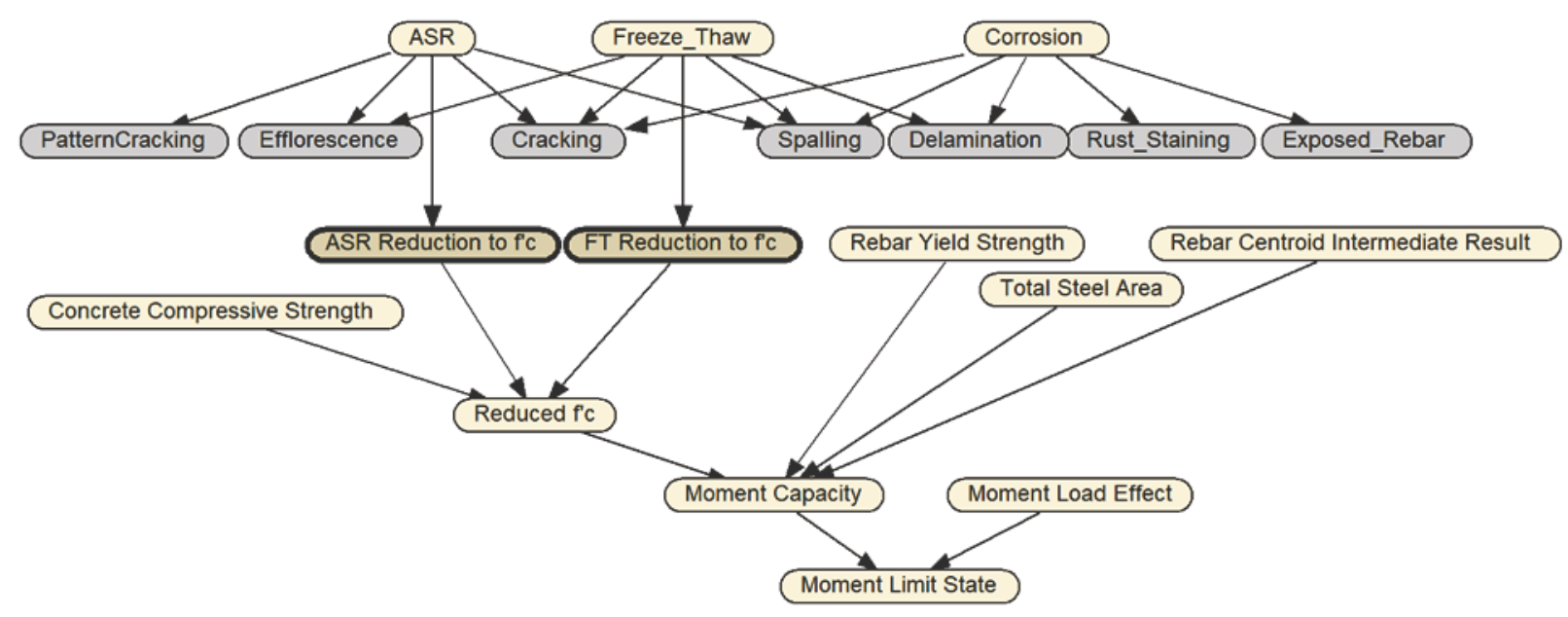


Table 4. Parameters of random variables.

\begin{tabular}{|c|c|c|c|c|c|}
\hline \multicolumn{3}{|c|}{ Parameter } & \multicolumn{3}{|c|}{ Distribution } \\
\hline Description & $\begin{array}{l}\text { Sym } \\
\text { bol }\end{array}$ & $\begin{array}{l}\text { Unit } \\
\text { s }\end{array}$ & $\begin{array}{c}\text { Bia } \\
\mathbf{s}\end{array}$ & $\mathrm{COV}$ & Reference \\
\hline $\begin{array}{l}\text { Concrete compressive } \\
\text { strength }\end{array}$ & $f_{\mathrm{c}}^{\prime}$ & ksi & $\begin{array}{l}1.1 \\
0\end{array}$ & 0.18 & LeBeau (2008) \\
\hline Rebar yield strength & $f_{\mathrm{y}}$ & ksi & $\begin{array}{l}1.1 \\
3\end{array}$ & 0.12 & Nowak et al. (1994) \\
\hline $\begin{array}{l}\text { Area of steel in rebar } \\
\text { layer } i\end{array}$ & $A_{i}$ & in. ${ }^{2}$ & $\begin{array}{l}1.0 \\
0\end{array}$ & 0.015 & $\begin{array}{l}\text { Nowak and Szerszen } \\
\text { (2003) }\end{array}$ \\
\hline $\begin{array}{l}\text { Centroid position of } \\
\text { rebar layer } i\end{array}$ & $y_{i}$ & in. & $\begin{array}{l}1.0 \\
0\end{array}$ & $\begin{array}{l}\text { St dev }{ }^{1}= \\
0.7 \text { in. }\end{array}$ & $\begin{array}{l}\text { Nowak and Szerszen } \\
\text { (2003) }\end{array}$ \\
\hline $\begin{array}{l}\text { Total moment load } \\
\text { effect }\end{array}$ & $M_{\mathrm{Q}}$ & $\begin{array}{l}\text { kip- } \\
\text { in. }\end{array}$ & $\begin{array}{l}1.1 \\
0\end{array}$ & 0.18 & $\begin{array}{l}\text { Roberts et al. } \\
\text { (2019); } \\
\text { LeBeau (2008) }\end{array}$ \\
\hline
\end{tabular}

${ }^{1}$ Because the error in positioning rebar does not change based on the depth of the member, the variability is given in terms of the standard deviation rather than the COV.

Note that the normal distribution was chosen mainly due to a lack of information to support other more complex distributions. The BN approach is not limited to normal distributions; future models could incorporate other distributions, represented either analytically or empirically (e.g., as tabular data).

The top two rows of nodes in Figure 2 are the portion of the BN related to material defects. The top row contains the underlying deterioration mechanisms described in Chapter 2: ASR, FT cycling, and corrosion. The second row contains the observed defects (Chapter 2). Based on the observed defects entered for the section, an inference is made on the probability distributions for the severity of each of the underlying deterioration mechanisms. Inference is performed by Netica, using message passing in a junction tree of cliques (Spiegelhalter et al. 1993; Jensen 1996; Neapolitan 2012).

Currently, the effect of deterioration is incorporated only for concrete compressive strength. Plans for future work include updating the BN to include the effect of corrosion on the remaining area of reinforcing steel.

Approximate reductions to the concrete compressive strength for the three idealized ASR and FT severity levels are given in Table 5. These numbers were selected by expert elicitation based on laboratory data and should not be considered precise estimates due to the wide range of conditions that 
may be encountered in the field. However, they are sufficient for performing inference.

Table 5. Concrete compressive strength reductions based on deterioration.

\begin{tabular}{|l|l|l|}
\hline \multirow{2}{*}{ Severity of deterioration } & \multicolumn{2}{|c|}{ Reduction to concrete compressive strength } \\
\cline { 2 - 3 } & \multicolumn{1}{|c|}{ ASR } & \multicolumn{1}{c|}{ FT } \\
\hline Low & 0.98 & 0.95 \\
\hline Moderate & 0.70 & 0.75 \\
\hline Severe & 0.40 & 0.45 \\
\hline
\end{tabular}

The minimum (i.e., most severe) reduction factor is applied to the concrete compressive strength as

$$
f_{\mathrm{c}, \text { reduced }}^{\prime}=f_{\mathrm{c}}^{\prime} \min \left(r_{\mathrm{ASR}}, r_{\mathrm{FT}}\right)
$$

where

$$
\begin{aligned}
r_{\mathrm{ASR}} & =\text { reduction to concrete compressive strength due to ASR } \\
r_{\mathrm{FT}} & =\text { reduction to concrete compressive strength due to FT. }
\end{aligned}
$$

The nominal moment capacity at the section is calculated as

$$
M_{\mathrm{n}}=f_{\mathrm{y}} A_{\text {total }}\left(h-\frac{S}{A_{\text {total }}}-\frac{1}{2} \cdot \frac{f_{\mathrm{y}} A_{\text {total }}}{0.85 f_{\mathrm{c}, \text { reduced }}^{\prime} b}\right)
$$

where

$$
\begin{aligned}
A_{\text {total }}= & \text { total area of steel, } \sum_{i} A_{i} \\
h, b= & \text { height and width of the girder, respectively (assumed to be } \\
& \text { deterministic in this analysis) } \\
S= & \text { first moment of area, } \sum_{i} A_{i} y_{i} .
\end{aligned}
$$

All other variables have been previously defined. For details on this calculation, refer to Appendix B. The individual rebar layers are "reduced" into $A_{\text {total }}$ and $S$ for efficiency, with the distributions of these two variables calculated prior to forming the $\mathrm{BN}$.

The equation for the moment limit state is obtained by writing equation (2) in terms of the moment capacity and the moment demand for the girder. 


$$
g_{\mathrm{M}}=M_{\mathrm{n}}-M_{Q}
$$

The probability of failure, $P_{\mathrm{f}}$, is the probability that $g_{\mathrm{M}}<0$. This probability is calculated based on the probability table computed by Netica for the node $g_{\mathrm{M}}$. 


\section{Programmatic Generation of Bayesian Networks}

The previous chapter described the process for making inferences on the probability of failure (or, equivalently, the reliability) of a girder at a particular cross section. Of course, for realistic problems, the probability of failure of an entire girder or bridge will be of interest. The remaining chapters in this report discuss progress made towards analyzing reliability at the system level. This process starts with analyzing the reliability of a single girder, which can be viewed as a system composed of multiple cross sections acting in series. Such an analysis involves multiple BNs, which would be time-consuming for the user to create. This chapter describes the framework used for automatic generation of BNs given model parameters as inputs. Chapter 5 provides details related to the implementation.

Model development and exploration were initially performed by using Netica 6.04 (Norsys 2017). This software allowed for creation and analysis of BNs within a convenient graphical user interface (GUI). However, a major thrust of this project was the development of a tool to create BNs automatically, given the relevant input, thus freeing the user from this somewhat tedious task. Automation is also a crucial steppingstone toward eventual application of the BN models developed in this work.

The Python API (application programming interface) for Netica (Norsys 2018) was used to create a prototype GUI for creation and analysis of BNs for bridge reliability. The Bayesian inference calculations were performed by the Netica API. Python (version 3.7.3) provided a high-level, interpreted language for rapid development of a GUI using the tkinter library to interface with Tcl/Tk (version 8.6).

The following two prototype programs were created. Currently, the programs support only reinforced concrete girder bridges. As future projects require, the programs may be expanded to include steel girder bridges and prestressed concrete girder bridges.

- Bridge Reliability: Create a sectional model of a bridge girder, enter defects, and make inferences on reliability (Figure 3).

- Girder Condition: Enter condition findings for a girder and automate analysis of the girder as a system (Figure 4). 
Examples of the use of each program are given in Appendix C.

Figure 3. Example of Bridge Reliability program.

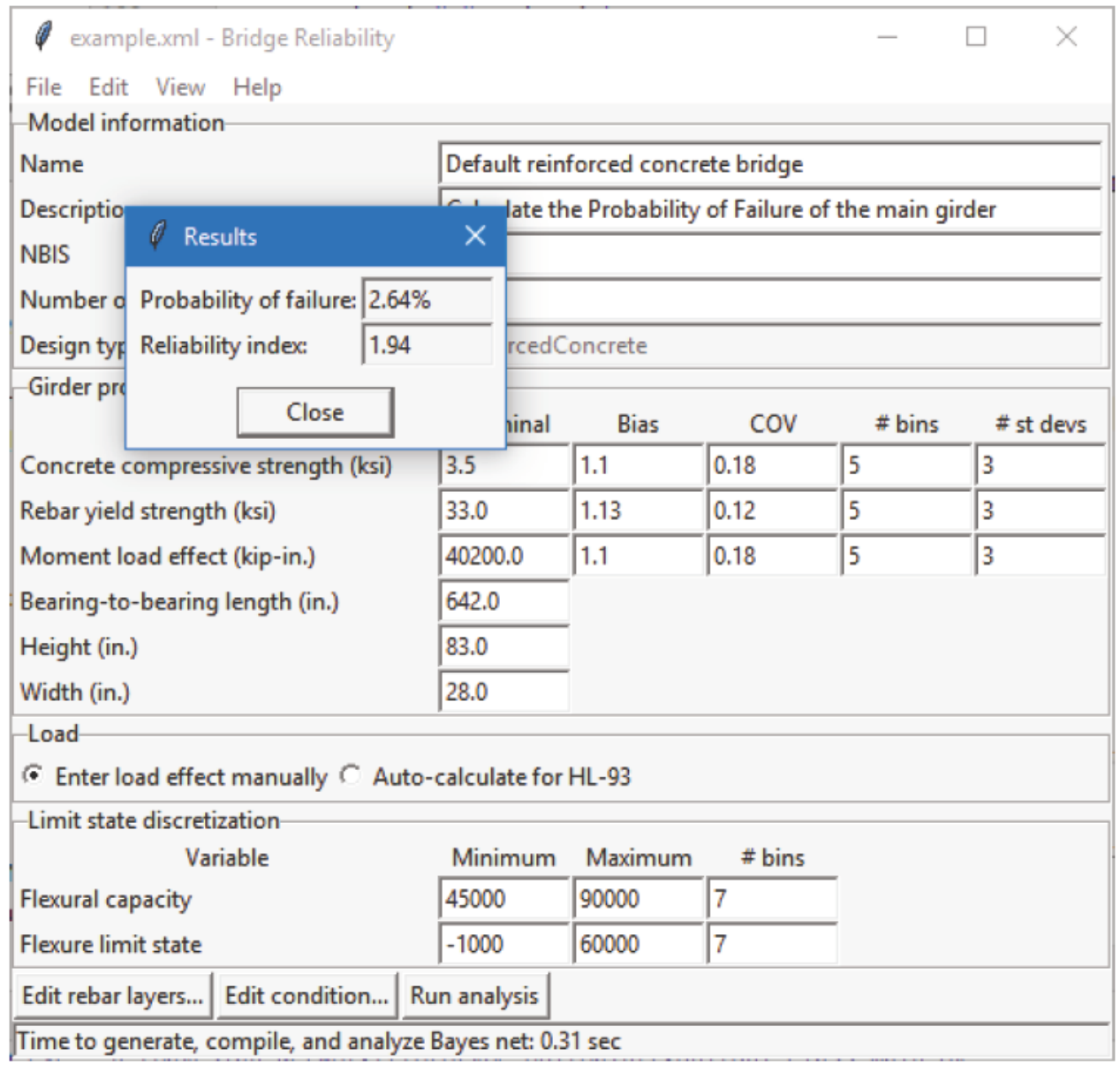


Figure 4. Example of Girder Condition program.

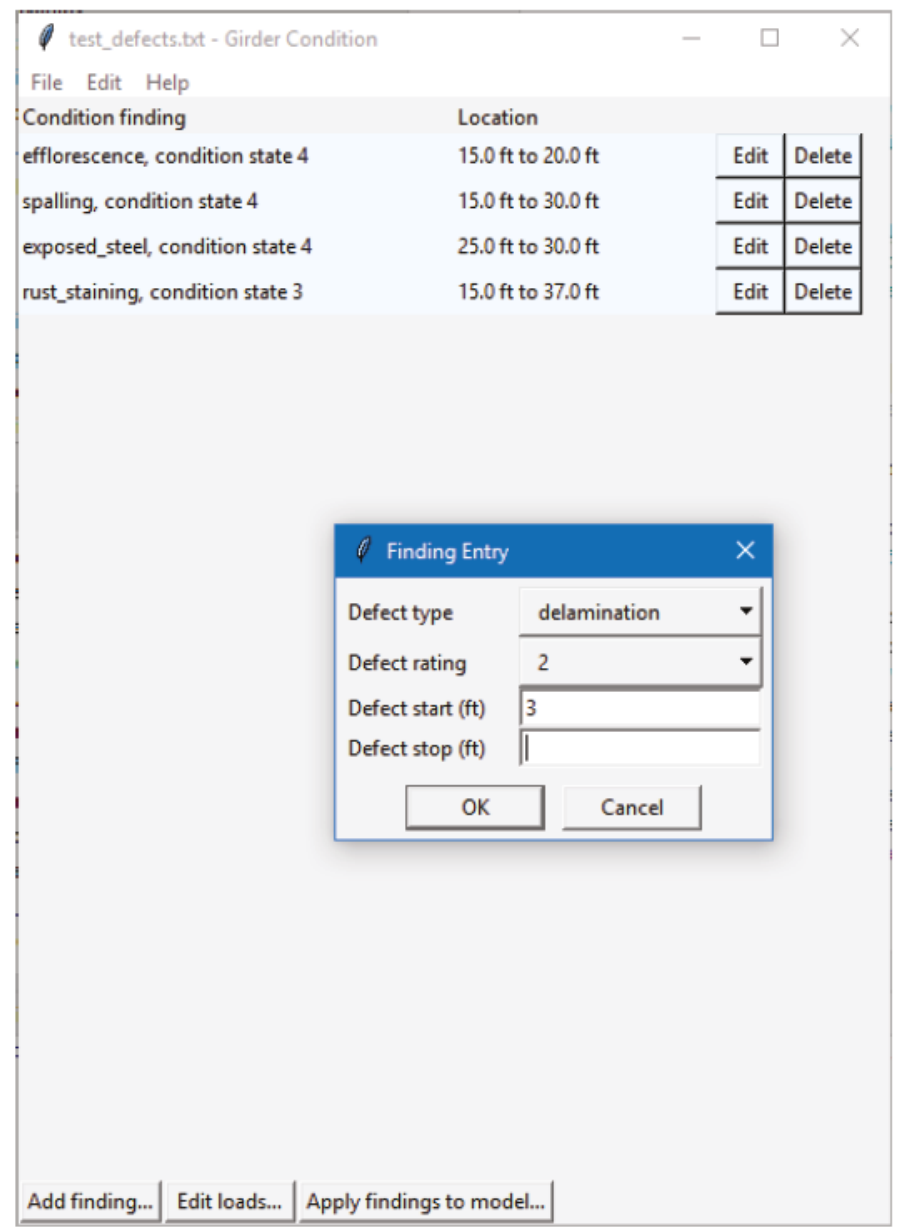




\section{Defects along the Girder Length}

This chapter provides details on the analysis of a girder with multiple defects along its length. Section 5.1 presents the overall approach and the assumptions that were made. Section 5.2 describes the procedure used to break the girder into a number of segments to be analyzed by using sectional analysis. Section 5.3 documents the method used to determine the maximum moment in each segment. Finally, Section 5.4 deals with the determination of girder reliability based on the reliability calculated by sectional analysis for each segment.

\subsection{Approach}

Inspection findings for defects are modeled as one or more individual defects on the girder. Each individual defect has a defect type, defect severity, start location, and stop location. To make inferences on the effect of these defects, which vary along the length of the girder, the next step is to divide the girder into a number of segments. Segments are selected so that the defect type(s) and severity (severities) are constant along the length of the segment. This work deals with reinforced concrete girders and assumes that the girder is prismatic and that the reinforcing steel does not vary along the length of the girder. Thus, the moment capacity is also constant along the length of the segment. However, the moment caused by the applied load varies along the length of the segment. This work assumes that the probability of failure of the segment can be determined by performing a sectional analysis at the point in the segment where the moment demand is greatest. A simple load-marching scheme is used to determine the maximum moment caused by the moving load(s). The probability of failure of the girder is determined by idealizing the girder as a system composed of a number of segments in series.

\subsection{Segmentation}

The segmentation process for a girder with findings for three defect types is illustrated in Figure 5. In this example, each defect region has start and stop locations (denoted by $x_{i}$ in the figure). Some of the defect regions overlap (defect 1 and defect 3 ) and others occur end-to-end (defect 2 and defect 3). In general, a girder is broken into segments as follows: 
Figure 5. Illustration of segmentation process for a girder.

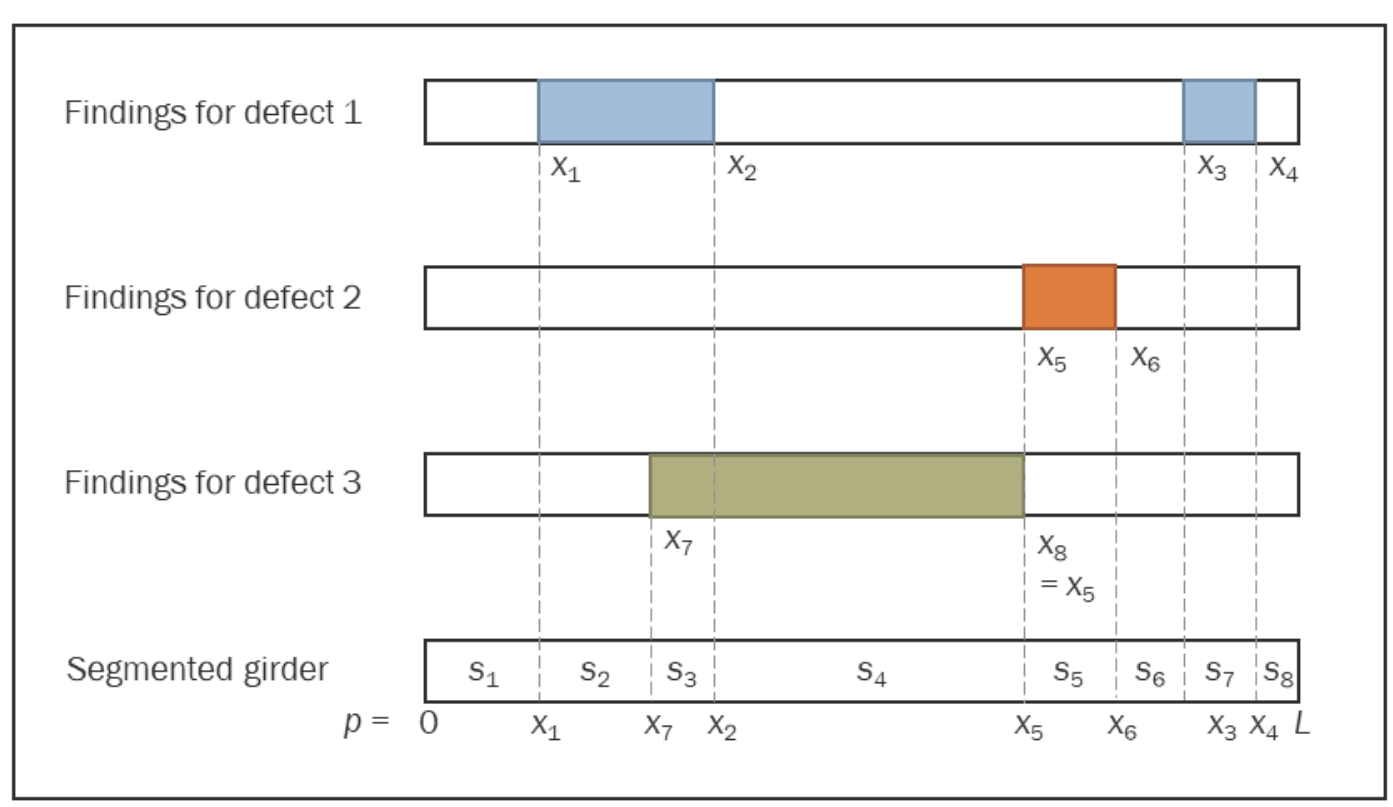

1. Determine the points, $p_{j}$, on the interior of the girder where divisions will be made. The number of division points is denoted $m$. These division points are all the unique values of $x_{i}$, where $x_{i}$ is the position where a defect starts or stops. Note that it is not important whether any given point is the beginning or end of a defect region for this step.

2. Sort the $p_{j}$ in ascending order.

3. Add the beginning and end of the girder to the division points: $p_{0}:=0$ and $p_{m+1}:=L$.

4. The girder is divided into $n=m+1$ segments. For $k=1,2, \ldots, n$, segment $s_{k}$ starts at point $p_{k-1}$ and ends at point $p_{k}$.

5. Finally, the defects are mapped onto the new segments.

This approach, dividing the girder into only as many segments as are needed, has two advantages over dividing the girder into uniform segments.

First, uniform segmentation can lead to inaccurate defect locations if the segments are not small enough. For example, suppose a 100 -ft-long girder is divided into $5-\mathrm{ft}$ segments starting from $0 \mathrm{ft}$. Suppose further that a defect occurs from $4 \mathrm{ft}$ to $6 \mathrm{ft}$. The defect touches two segments (i.e., $s_{1}$, from $0 \mathrm{ft}$ to $5 \mathrm{ft}$ and $s_{2}$, from $5 \mathrm{ft}$ to $10 \mathrm{ft}$ ). The defect can be applied to the uniform segments in four possible ways: 
1. Apply the defect to $s_{1}$,

2. Apply the defect to $s_{2}$,

3. Apply the defect to both $s_{1}$ and $s_{2}$, or

4. Apply the defect to neither segment.

None of these alternatives are a satisfying solution. Alternatives 1-3 artificially increase the size of the area affected by the defect, and alternative 4 simply ignores the defect.

If the segment size is decreased to overcome this limitation, the second disadvantage of uniform segmentation appears. The large number of segments needed for accurately locating defects results in longer analysis times.

\subsection{Maximum moment}

Currently, the program permits the specification of a uniformly distributed dead load along with a live load consisting of either of the following options:

- HL-93 (design truck or tandem, plus lane load) or

- Moving point load with specified magnitude.

A simple approach is used to determine the maximum moment. The program divides the girder into a number of finely spaced points at which the moment is computed. For each moment computation point, the load train (design truck, design tandem, or custom point load) is marched across the girder. The total moment due to the moving loads, lane load (if any), and dead load (if specified) is computed. If the total moment exceeds the previously maximum moment, then the maximum moment is updated. The location at which the maximum moment occurs and the position of the load train causing the maximum moment are also stored. If the HL-93 load combination is selected, three load trains are actually checked: design truck moving left-to-right, design truck moving right-to-left, and design tandem.

This approach uses one loop (load position) nested inside another loop (moment computation point). Thus, the number of moment calculations varies with the square of the number of points with which the girder is discretized. A slight coarsening of this discretization can result in a noticeable speedup. 
It is worth noting that the time required for maximum load computation does not increase with the number of segments. The number of moment computation points and the number of possible load positions depend only on the length of the girder and the point spacing.

\subsection{System reliability}

At this point, the girder has been broken into $n$ segments, with defect ratings and the maximum moment demand determined for each segment. The probability of failure, $P_{\mathrm{f}, i}$, for each segment $s_{i}$ is determined by using a sectional analysis (see Chapter 3 ) conducted at the location where the maximum moment occurs in that segment. The system probability of failure, $P_{\mathrm{f}, \text { sys }}$, for a girder with $n$ segments can be bounded as follows (Ayyub and McCuen 2003):

$$
\max _{1 \leq i \leq n} P_{\mathrm{f}, i}<P_{\mathrm{f}, \text { sys }}<1-\prod_{i=1}^{n}\left(1-P_{\mathrm{f}, i}\right) .
$$

The lower bound applies when the failure events of the components (i.e., the segments) are completely dependent, and the upper bound applies when the failure events of the components are completely independent.

Assuming that the failure events of the segments are completely independent leads to unphysical results. Figure 6 shows a pristine girder (i.e., completely free of defects) with two segmentations: (a) one segment and (b) two segments. The girder is simply supported and is loaded by a moving point load of magnitude $P$. The maximum moment demand for all segments, for both case (a) and case (b), occurs when $P$ is at midspan. Because the girder has no defects, the moment capacity is the same in all segments. Although both cases are the same girder, the upper bound from case (a) is $P_{\mathrm{f}, \text { sys }}<x$, whereas case (b) gives $P_{\mathrm{f}, \text { sys }}<2 x-x^{2}$. Clearly, however, the failure events of segments $s_{1}$ and $s_{2}$ are not independent. A load at midspan that caused $s_{1}$ to fail would also cause $s_{2}$ to fail. More generally, the failure of multiple segments may not be as completely dependent as this simple example. However, segments cannot be loaded in isolation; a load somewhere on a simply supported girder will result in some distribution of bending moment along the entire length of the girder. Therefore, the failure of girder segments is at least partially dependent. Further investigation is needed to determine how best to account for this dependence in system-level reliability. 
Figure 6. Effect of segmentation on computed probability of failure.

(a) Pristine girder, 1 segment

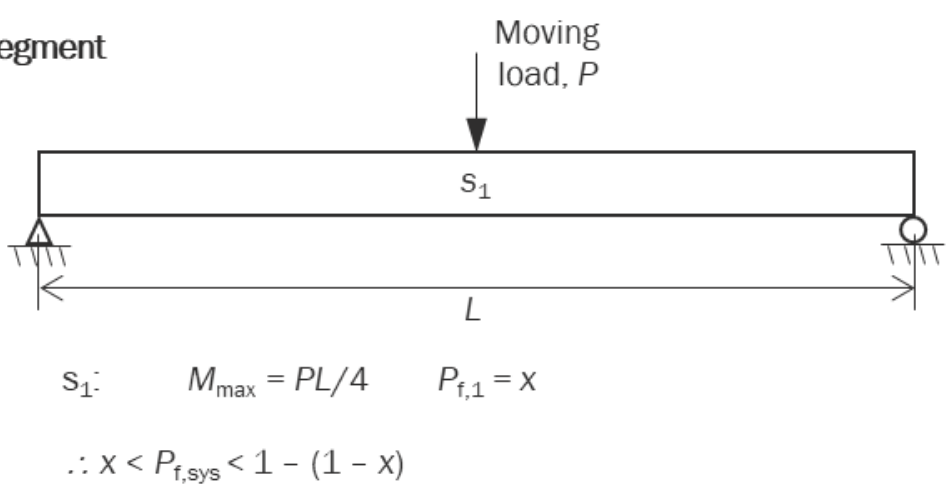

(b) Pristine girder, 2 segments

Moving

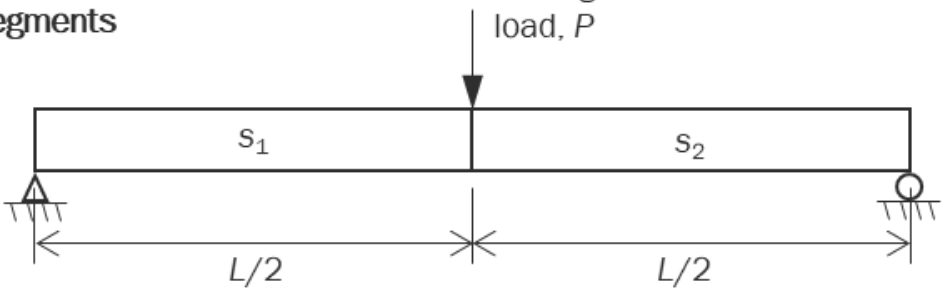

$$
\begin{array}{lrl}
\mathrm{s}_{1}: \quad M_{\max }=P L / 4 & P_{\mathrm{f}, 1}=x \\
\mathrm{~s}_{2}: \quad M_{\max }=P L / 4 & P_{\mathrm{f}, 2}=x
\end{array}
$$




\section{Summary}

This report summarizes progress on the development of BNs for making inferences on the reliability of RC girder bridges based on inspection observations. Key milestones in this development include the following:

- Relationships were determined both between observed defects and underlying deterioration mechanisms for concrete and between deterioration mechanisms and mechanical property reductions. These relationships are crucial to the incorporation of defects into reliability inference. At present, they are based largely on expert elicitation due to a lack of experimental data that match field conditions.

- A BN that incorporates the effects of ASR and FT deterioration on concrete compressive strength was developed for inferences on RC girder reliability.

- Two prototype programs were written to automate the procedure for reliability inference.

- The program Bridge Reliability automatically creates and analyzes $\mathrm{BNs}$ for RC girders. This program provides a streamlined interface to enter the required girder and loading parameters.

- The program Girder Condition performs reliability inference for an $\mathrm{RC}$ girder with spatially varying defects. The girder is automatically segmented for sectional analysis. The maximum moment for each segment is determined for a uniform dead load and a live load that can consist of either the HL-93 loading or a moving point load.

With more development, this BN tool can be used to compare conditions of bridges relative to one another and aid in the prioritization of repairs. However, an extensive survey of bridges affected by deterioration mechanisms is needed to confidently establish valid relationships between deterioration severity and mechanical properties. The survey would include visual inspections using $M B E I$ guidelines followed by concrete sampling and testing. Bridges of varying deterioration should be evaluated.

The above survey is crucial to build confidence in the $\mathrm{BN}$ tool. Other possible areas for future work include the following:

- Update the BN to include the effect of corrosion on the remaining area of reinforcing steel. 
- Explore the extent to which the failure events for girder segments are dependent or independent (see Section 5.4).

- Extend the analysis to operate at the level of a bridge rather than a single girder.

- Develop a similar procedure (BN and accompanying programs to automate analysis) for steel girder bridges.

- Apply this general procedure to steel navigation structures. 


\section{References}

AASHTO (American Association of State Highway and Transportation Officials). 2013. Manual for bridge element inspection. Washington, DC: American Association of State Highway and Transportation Officials.

Ayachit, U. 2018. The ParaView guide community edition: Updated for ParaView version 5.5. Clifton Park, NY: Kitware Inc. http://www.paraview.org/download/.

Ayyub, B. M., and R. H. McCuen. 2003. Probability, statistics, and reliability for engineers and scientists. Boca Raton, FL: Chapman \& Hall/CRC Press.

Giaccio, G., R. Zerbino, J. Ponce, and O. R. Batic. 2008. Mechanical behavior of concretes damaged by alkali-silica reaction. Cement and Concrete Research 38(7):9931004.

Hanjari, K. Z., P. Utgenannt, and K. Lundgren. 2011. Experimental study of the material and bond properties of frost-damaged concrete. Cement and Concrete Research 41(3):244-54.

Heckerman, D., and M. P. Wellman. 1995. Bayesian networks. Communications of the ACM 38(3):27-30.

Jensen, F. V. 1996. An introduction to Bayesian networks. London: UCL Press.

Ji, X., Y. Song, and Y. Liu. 2008. Effect of freeze-thaw cycles on bond strength between steel bars and concrete. Journal of Wuhan University of Technology-Materials Science Edition 23(4):584-88.

LeBeau, K. 2008. A bi-directional load rating model of the flexural response of a prestressed concrete bridge beam element. PhD diss., Northeastern University.

Liu, C., G. Chen, G. Ji, X. Kong, and L. Ma. 2012. The effect of AAR on concrete mechanical properties. In Second International Conference on MicrostructuralRelated Durability of Cementitious Composites, 568-576. Amsterdam: RILEM Publications SARL.

McDonald, J. E. 1987. Rehabilitation of navigation lock walls: Case histories. REMRCS-13. Vicksburg, MS: Army Engineer Waterways Experiment Station.

Neapolitan, R. E. 2012. Probabilistic reasoning in expert systems: Theory and algorithms. CreateSpace Independent Publishing Platform (reprint of 1990 edition.) New York: John Wiley \& Sons.

Norsys. 2017. Netica (version 6.04). Vancouver, Canada: Norsys Software Corp. 2018. NeticaPy (version 0.72). Vancouver, Canada: Norsys Software Corp.

Nowak, A. S., and K. R. Collins. 2012. Reliability of structures. Boca Raton, FL: CRC Press. 
Nowak, A. S., and M. M. Szerszen. 2003. Calibration of design code for buildings (ACI 318): Part 1-Statistical models for resistance. ACI Structural Journal 100(3):37782.

Nowak, A. S., A. S. Yamani, and S. W. Tabsh. 1994. Probabilistic models for resistance of concrete bridge girders. Structural Journal 91(3):269-76.

Pradhan, M., M. Henrion, G. Provan, B. Del Favero, and K. Huang. 1996. The sensitivity of belief networks to imprecise probabilities: an experimental investigation. Artificial Intelligence 85(1-2):363-97.

Qin, X., S. Meng, D. Cao, Y. Tu, N. Sabourova, N. Grip, U. Ohlsson, T. Blanksvärd, G. Sas, and L. Elfgren. 2016. Evaluation of freeze-thaw damage on concrete material and prestressed concrete specimens. Construction and Building Materials 125:892904.

Roberts, J. M., E. Ruiz, A. B. Groeneveld, and R. Pérez-Gracia. 2019. Use of Bayesian networks for inferences on bridge safety. In Proceedings of the 98th Annual Meeting of the Transportation Research Board, paper no. 19-04278. Washington, D.C.: Transportation Research Board.

Seijas-Macías, A., and A. Oliveira. 2012. An approach to distribution of the product of two normal variables. Discussiones Mathematicae Probability and Statistics 32:8799. https://doi.org/doi:10.7151/dmps.1146.

Shang, H., W. Cao, and B. Wang. 2014. Effect of fast freeze-thaw cycles on mechanical properties of ordinary-air-entrained concrete. The Scientific World Journal. http://dx.doi.org/10.1155/2014/923032.

Smaoui, N., B. Bissonnette, M.-A. Bérubé, B. Fournier, and B. Durand. 2005. Mechanical properties of ASR-affected concrete containing fine or coarse reactive aggregates. Journal of ASTM International 3(3):1-16.

Spiegelhalter, D. J., A. P. Dawid, S. L. Lauritzen, and R. G. Cowell. 1993. Bayesian analysis in expert systems. Statistical Science 8(3):219-47.

Swamy, R., and M. Al-Asali. 1988. Engineering properties of concrete affected by alkalisilica reaction. Materials Journal 85(5):367-74.

Thomas, M., B. Fournier, K. Folliard, and Y. Resendez. 2012. Alkali-silica reactivity surveying and tracking guidelines. FHWA-HIF-12-046. Washington, D.C.: Federal Highway Administration. 


\section{Appendix A: Defect Conditional Probability Tables}

This appendix presents the complete CPTs used to determine defect condition states based on the severity of the underlying deterioration mechanisms. These CPTs (Table A1 through Table B1) are based on expert elicitation. Note that all probabilities are expressed as percentages. To permit easy updating without requiring changes to the source code for Bridge Reliability, the CPTs are saved as tab-separated value files.

Table A1. CPT for cracking severity.

\begin{tabular}{|c|c|c|c|c|c|c|}
\hline ASR & $\mathrm{FT}$ & Corrosion & 1 & 2 & 3 & 4 \\
\hline Low & Low & Low & 90 & 5 & 4 & 1 \\
\hline Low & Low & Moderate & 10 & 37 & 38 & 15 \\
\hline Low & Low & Severe & 5 & 10 & 15 & 70 \\
\hline Low & Moderate & Low & 15 & 35 & 30 & 20 \\
\hline Low & Moderate & Moderate & 8 & 15 & 27 & 50 \\
\hline Low & Moderate & Severe & 2 & 10 & 13 & 75 \\
\hline Low & Severe & Low & 5 & 15 & 30 & 50 \\
\hline Low & Severe & Moderate & 2 & 8 & 37 & 53 \\
\hline Low & Severe & Severe & 2 & 6 & 32 & 60 \\
\hline Moderate & Low & Low & 5 & 30 & 40 & 25 \\
\hline Moderate & Low & Moderate & 8 & 17 & 50 & 25 \\
\hline Moderate & Low & Severe & 5 & 15 & 30 & 50 \\
\hline Moderate & Moderate & Low & 5 & 25 & 30 & 40 \\
\hline Moderate & Moderate & Moderate & 3 & 17 & 30 & 50 \\
\hline Moderate & Moderate & Severe & 1 & 10 & 34 & 55 \\
\hline Moderate & Severe & Low & 2 & 7 & 21 & 70 \\
\hline Moderate & Severe & Moderate & 1 & 4 & 30 & 65 \\
\hline Moderate & Severe & Severe & 1 & 2 & 27 & 70 \\
\hline Severe & Low & Low & 1 & 7 & 12 & 80 \\
\hline Severe & Low & Moderate & 1 & 4 & 13 & 82 \\
\hline Severe & Low & Severe & 1 & 2 & 7 & 90 \\
\hline Severe & Moderate & Low & 1 & 5 & 12 & 82 \\
\hline Severe & Moderate & Moderate & 1 & 4 & 23 & 72 \\
\hline Severe & Moderate & Severe & 1 & 1 & 8 & 90 \\
\hline Severe & Severe & Low & 1 & 4 & 10 & 85 \\
\hline Severe & Severe & Moderate & 1 & 1 & 8 & 90 \\
\hline Severe & Severe & Severe & 1 & 1 & 3 & 95 \\
\hline
\end{tabular}


Table A2. CPT for delamination severity.

\begin{tabular}{|c|c|c|c|c|c|}
\hline $\mathrm{FT}$ & Corrosion & 1 & 2 & 3 & 4 \\
\hline Low & Low & 95 & 3 & 1 & 1 \\
\hline Low & Moderate & 20 & 32 & 33 & 15 \\
\hline Low & Severe & 10 & 26 & 26 & 38 \\
\hline Moderate & Low & 10 & 38 & 40 & 12 \\
\hline Moderate & Moderate & 10 & 25 & 35 & 30 \\
\hline Moderate & Severe & 8 & 15 & 35 & 42 \\
\hline Severe & Low & 3 & 12 & 35 & 50 \\
\hline Severe & Moderate & 3 & 7 & 35 & 55 \\
\hline Severe & Severe & 1 & 4 & 30 & 65 \\
\hline
\end{tabular}

Table A3. CPT for efflorescence severity.

\begin{tabular}{|l|l|r|r|r|r|}
\hline \multicolumn{1}{|c|}{ ASR } & \multicolumn{1}{c|}{ FT } & \multicolumn{1}{c|}{$\mathbf{1}$} & \multicolumn{1}{c|}{$\mathbf{2}$} & \multicolumn{1}{c|}{$\mathbf{3}$} & \multicolumn{1}{c|}{$\mathbf{4}$} \\
\hline Low & Low & 90 & 5 & 4 & 1 \\
\hline Low & Moderate & 50 & 30 & 15 & 5 \\
\hline Low & Severe & 15 & 30 & 30 & 25 \\
\hline Moderate & Low & 10 & 35 & 35 & 20 \\
\hline Moderate & Moderate & 10 & 30 & 35 & 25 \\
\hline Moderate & Severe & 5 & 20 & 35 & 40 \\
\hline Severe & Low & 1 & 9 & 15 & 75 \\
\hline Severe & Moderate & 1 & 4 & 20 & 75 \\
\hline Severe & Severe & 1 & 1 & 18 & 80 \\
\hline
\end{tabular}

Table A4. CPT for exposed rebar severity.

\begin{tabular}{|l|r|r|r|r|}
\hline Corrosion & \multicolumn{1}{|c|}{1} & \multicolumn{1}{|c|}{$\mathbf{2}$} & \multicolumn{1}{c|}{$\mathbf{3}$} & \multicolumn{1}{c|}{$\mathbf{4}$} \\
\hline Low & 90 & 5 & 4 & 1 \\
\hline Moderate & 10 & 35 & 35 & 20 \\
\hline Severe & 5 & 20 & 25 & 50 \\
\hline
\end{tabular}

Table A5. CPT for pattern cracking occurrence.

\begin{tabular}{|l|r|r|}
\hline \multicolumn{1}{|c|}{ ASR } & \multicolumn{1}{c|}{ Yes } & \multicolumn{1}{c|}{ No } \\
\hline Low & 10 & 90 \\
\hline Moderate & 80 & 20 \\
\hline Severe & 90 & 10 \\
\hline
\end{tabular}


Table A6. CPT for rust staining severity.

\begin{tabular}{|l|r|r|r|r|}
\hline Corrosion & \multicolumn{1}{|c|}{ 1 } & \multicolumn{1}{|c|}{$\mathbf{2}$} & \multicolumn{1}{|c|}{$\mathbf{3}$} & \multicolumn{1}{|c|}{$\mathbf{4}$} \\
\hline Low & 90 & 5 & 4 & 1 \\
\hline Moderate & 11 & 32 & 32 & 25 \\
\hline Severe & 1 & 9 & 15 & 75 \\
\hline
\end{tabular}

Table A7. CPT for spalling severity.

\begin{tabular}{|c|c|c|c|c|c|c|}
\hline ASR & $\mathrm{FT}$ & Corrosion & 1 & 2 & 3 & 4 \\
\hline Low & Low & Low & 95 & 3 & 1 & 1 \\
\hline Low & Low & Moderate & 15 & 25 & 35 & 25 \\
\hline Low & Low & Severe & 5 & 25 & 30 & 40 \\
\hline Low & Moderate & Low & 15 & 37 & 38 & 10 \\
\hline Low & Moderate & Moderate & 10 & 20 & 25 & 45 \\
\hline Low & Moderate & Severe & 3 & 12 & 25 & 60 \\
\hline Low & Severe & Low & 5 & 20 & 25 & 50 \\
\hline Low & Severe & Moderate & 3 & 10 & 22 & 65 \\
\hline Low & Severe & Severe & 3 & 4 & 8 & 85 \\
\hline Moderate & Low & Low & 15 & 45 & 30 & 10 \\
\hline Moderate & Low & Moderate & 2 & 18 & 25 & 55 \\
\hline Moderate & Low & Severe & 5 & 15 & 20 & 60 \\
\hline Moderate & Moderate & Low & 10 & 32 & 33 & 25 \\
\hline Moderate & Moderate & Moderate & 3 & 7 & 30 & 60 \\
\hline Moderate & Moderate & Severe & 2 & 8 & 15 & 75 \\
\hline Moderate & Severe & Low & 2 & 8 & 25 & 65 \\
\hline Moderate & Severe & Moderate & 2 & 3 & 8 & 87 \\
\hline Moderate & Severe & Severe & 2 & 3 & 5 & 90 \\
\hline Severe & Low & Low & 4 & 10 & 26 & 60 \\
\hline Severe & Low & Moderate & 2 & 10 & 23 & 65 \\
\hline Severe & Low & Severe & 2 & 5 & 13 & 80 \\
\hline Severe & Moderate & Low & 2 & 8 & 25 & 65 \\
\hline Severe & Moderate & Moderate & 2 & 4 & 6 & 88 \\
\hline Severe & Moderate & Severe & 1 & 4 & 5 & 90 \\
\hline Severe & Severe & Low & 1 & 9 & 15 & 75 \\
\hline Severe & Severe & Moderate & 2 & 3 & 5 & 90 \\
\hline Severe & Severe & Severe & 1 & 2 & 2 & 95 \\
\hline
\end{tabular}




\section{Appendix B: Efficient Network Structure}

The structure of a BN has a large influence on the efficiency of analysis, from creating CPTs to compiling the network to performing inference. This appendix begins by examining the efficiency of the $\mathrm{BN}$ for RC moment capacity introduced in Section 3.3. All of the nodes in the model represent continuous numeric variables, and CPTs for the nodes are generated by random sampling. The size of the CPTs directly influences the number of function evaluations that must be performed when randomly sampling, as well as the amount of memory required to perform inference on the $\mathrm{BN}$. Thus, the amount of time required for analysis can be decreased by reducing the size of the CPTs. Two methods are discussed for reducing the size of the CPTs by reducing the dimensionality of a CPT.

\section{Cause of the problem}

Initial model development for RC bridges created nodes for the area, $A_{i}$, and centroid position, $y_{i}$, of each rebar layer. This allows fine-grained control of the uncertainty for the individual layers. Inference can also be performed on individual layers. The main disadvantage to this approach is that the size of the CPT for the nominal moment capacity, $M_{\mathrm{n}}$, grows exponentially with the number of rebar layers, $n$.

An example with three rebar layers is shown in Figure 7. The other nodes appearing in the $\mathrm{BN}$ are the 28-day concrete unconfined compressive strength, $f_{\mathrm{c}}^{\prime}$, and the steel tensile yield strength, $f_{\mathrm{y}}$. If all nodes are discretized into $d$ bins, then the size of the CPT inputs for $M_{\mathrm{n}}$ is $d^{2 n+2}$. The total number of CPT entries in the $\mathrm{BN}$ is $d^{2 n+3}+(2 n+2) d$. Clearly, a better solution is needed. 
Figure B1. Naïve BN for RC moment capacity.

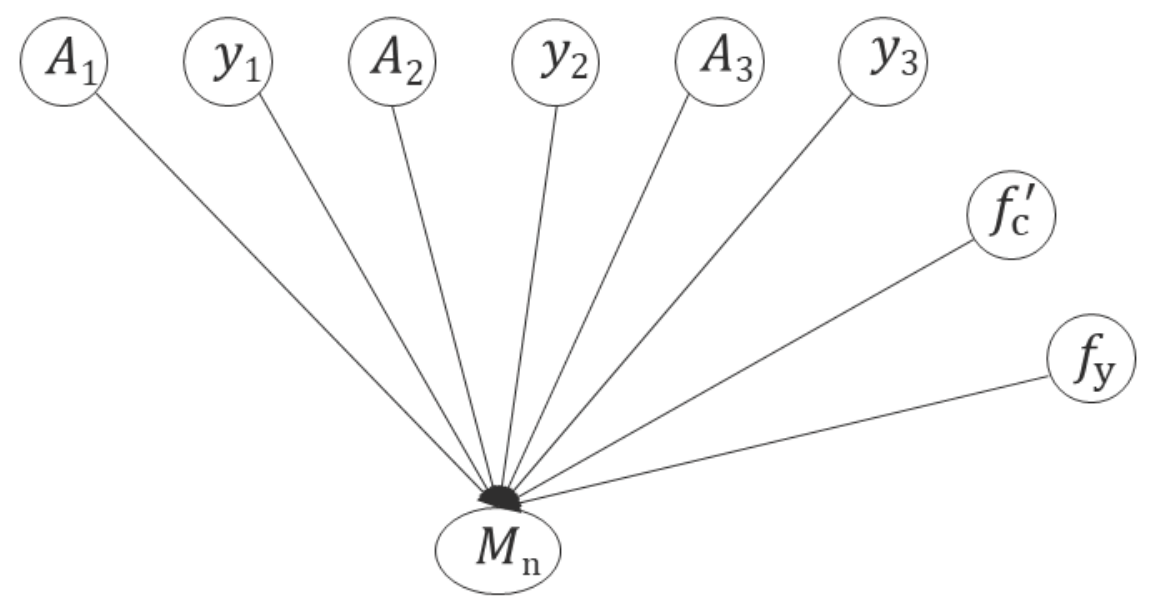

\section{Variable reduction}

One idea is to take arbitrarily many $A_{i}$ 's and $y_{i}$ 's as input and reduce them into a fixed number of variables that are included in the BN. This can be done by recognizing that the equation for $M_{\mathrm{n}}$ requires only the total area of steel and the centroid of all steel layers.

$$
M_{\mathrm{n}}=f_{\mathrm{y}} A_{\text {total }}\left(h-\bar{y}-\frac{1}{2} \cdot \frac{f_{\mathrm{y}} A_{\text {total }}}{0.85 f_{\mathrm{c}}^{\prime} b}\right)
$$

where

$$
\begin{aligned}
A_{\text {total }}= & \text { total area of steel, } \sum_{i} A_{i} \\
h, b= & \text { height and width of the girder, respectively, (assumed to be } \\
& \text { deterministic in this analysis) } \\
\bar{y}= & \text { centroid of all steel layers, }\left(\sum_{i} A_{i} y_{i}\right) / \sum_{i} A_{i} .
\end{aligned}
$$

Now, the task is to analytically determine (or approximate) the distributions of $A_{\text {total }}$ and $\bar{y}$. As will be shown, it is convenient to rewrite $\bar{y}$ to allow for easier approximation. Calculating these distributions outside the $\mathrm{BN}$ will significantly reduce the size of the network.

Currently, $A_{i}$ and $y_{i}$ are assumed to be normally distributed. The total area of steel is the sum of $n$ normally distributed variables, $\sum_{i} A_{i}$, which is also normally distributed. The expectation and variance of the sum (Ayyub and McCuen 2003) are simple to express and are given below. 


$$
\begin{aligned}
\mathrm{E}\left(A_{\text {total }}\right) & =\sum_{i} \mathrm{E}\left(A_{i}\right), \\
\operatorname{Var}\left(A_{\text {total }}\right) & =\sum_{i} \operatorname{Var}\left(A_{i}\right),
\end{aligned}
$$

where

$$
\begin{aligned}
\mathrm{E}(\cdot) & =\text { expectation operator } \\
\operatorname{Var}(\cdot) & =\text { variance operator. }
\end{aligned}
$$

Analytically determining the distribution of the centroid location would be complicated, as $\bar{y}$ is a rational function. However, $\bar{y}$ can be rewritten as $\bar{y}=$ $S / A_{\text {total }}$, where $S=\sum_{i} A_{i} y_{i}$ is the first moment of area. The first moment of area is the sum of $n$ products of normally distributed variables. Although $S$ cannot be represented exactly by using a normal distribution, it can be approximated sufficiently well for these purposes, as will be shown below.

The product of two normally distributed random variables, $X \sim \mathcal{N}\left(\mu_{x}, \sigma_{x}^{2}\right)$ and $Y \sim \mathcal{N}\left(\mu_{y}, \sigma_{y}^{2}\right)$, is the sum of two $\chi^{2}$ random variables:

$$
X Y=\frac{1}{4}(X+Y)^{2}-\frac{1}{4}(X-Y)^{2}
$$

The sum (or difference) $X \pm Y$ follows a normal distribution, and therefore its square follows a $\chi^{2}$ distribution.

This would be overly complex for making inferences based on (semi-) subjective inspection findings. However, as shown by Seijas-Macías and Oliveira (2012), the distribution of $X Y$ can be approximated as normal. The quality of this approximation depends on the inverse coefficient of variation $(\mathrm{COV})$, defined as

$$
\delta_{x}=\frac{\mu_{x}}{\sigma_{x}}, \quad \delta_{y}=\frac{\mu_{y}}{\sigma_{y}} .
$$

The product $X Y$ approaches the distribution $\mathcal{N}\left(\mu_{x} \mu_{y}, \mu_{x}^{2} \sigma_{y}^{2}+\mu_{y}^{2} \sigma_{x}^{2}\right)$ as $\delta_{x}$ and $\delta_{y}$ increase. Seijas-Macías and Oliveira (2012) showed that the approximation was generally acceptable when $\delta_{x}>1$ and $\delta_{y}>1$. In our 
case, the COV for $A_{i}$ was assumed to be 0.015 (Nowak and Szerszen 2003), corresponding to $\delta_{A_{i}}=1 / 0.015 \approx 66.7 \gg 1$. Nowak and Szerszen (2003) gives a standard deviation of $0.7 \mathrm{in}$. for rebar vertical position. Due to clear cover requirements, the rebar height $y_{i}$ is unlikely to be less than 2.5 or 3 in. for the lowest layer. This corresponds to a $\delta_{y_{i}}$ of at least $2.5 / 0.7 \approx$ 3.57. Thus, this approximation is judged to be sufficient for our purposes.

Having found a normal distribution approximation for the product $A_{i} y_{i}$, the distribution of the sum $\sum_{i} A_{i} y_{i}$ can also be approximated as normal. The expectation and variance are then

$$
\begin{gathered}
\mathrm{E}(S) \approx \sum_{i} \mathrm{E}\left(A_{i}\right) \mathrm{E}\left(y_{i}\right), \\
\operatorname{Var}(S) \approx \sum_{i}\left(\mathrm{E}\left(y_{i}\right)\right)^{2} \operatorname{Var}\left(A_{i}\right)+\left(\mathrm{E}\left(A_{i}\right)\right)^{2} \operatorname{Var}\left(y_{i}\right) .
\end{gathered}
$$

The variance, equation (B7), assumes that the variables are uncorrelated. The resulting reduced $\mathrm{BN}$ is shown in Figure B2. The total size of the inputs to the CPT for $M_{\mathrm{n}}$ is $d^{4}$ and is independent of the number of layers of rebar. The total number of CPT entries is $d^{5}+4 d$.

Figure B2. BN for RC moment capacity using reduced variables for rebar geometric properties.

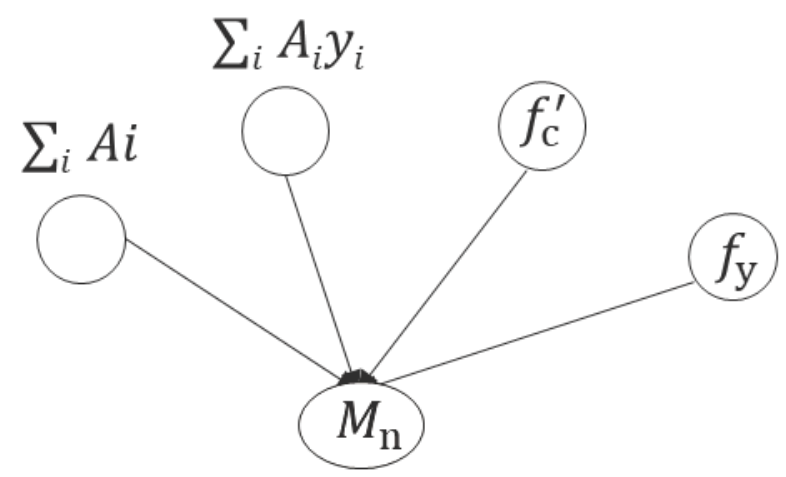

\section{Network unraveling}

The node with the most parents typically dominates the size of the CPT. This is because a node with $p$ parents requires a CPT with $p+$ 1 dimensions. The BN can be "unraveled" to yield a new BN where every 
node has at most two parents ${ }^{*}$, thereby limiting the CPTs to three dimensions. This reduces the memory required to store the CPT and the number of function evaluations required to populate the CPT by random sampling. However, there are two primary difficulties associated with unraveling. First, the number of nodes will still increase linearly with the number of rebar layers. Second, an appropriate discretization needs to be chosen for all of the intermediate nodes.

The issue of choosing appropriate discretizations for the intermediate nodes is significant, as it affects the accuracy of the probability distribution for the intermediate nodes as well as their child nodes. A discretization should cover the likely range of values the node can take on and provide enough bins so that the shape of the distribution is represented reasonably well. An appropriate discretization for an input variable, such as concrete 28-day compressive strength, may be determined so that the bins cover the mean value plus and minus a certain number of standard deviations, perhaps 3 . Having to determine, or even roughly estimate, the bins for a large number of intermediate nodes would be onerous.

The terms $\mathrm{A}_{\text {total }}$ and $S$, defined previously, are straightforward to decompose into two-operand subexpressions. The moment capacity, equation (B1), can be expressed as follows, remembering that $b$ and $h$ are assumed to be deterministic (constant) in the calculations.

$$
\begin{gathered}
T=f_{\mathrm{y}} A_{\text {total }}, \\
\bar{y}=\frac{S}{A_{\text {total }}}, \\
a=\frac{T}{0.85 f_{\mathrm{c}}^{\prime} b^{\prime}}, \\
\operatorname{arm}=h-\bar{y}-\frac{a}{2},
\end{gathered}
$$

* This is possible because the formulas in our simple BN are composed of the usual arithmetic operations, which take two operands. If, for example, functions or operators with an arity of three were present, then nodes in the unraveled BN would have at most three parents. 


$$
M_{\mathrm{n}}=T \cdot \operatorname{arm}
$$

The completely unraveled BN is shown in Figure B3. The number of CPT entries is broken down in Table B1. The total number of CPT entries is $(3 n+3) d^{3}+(2 n+2) d$.

Figure B3. Completely unraveled BN.

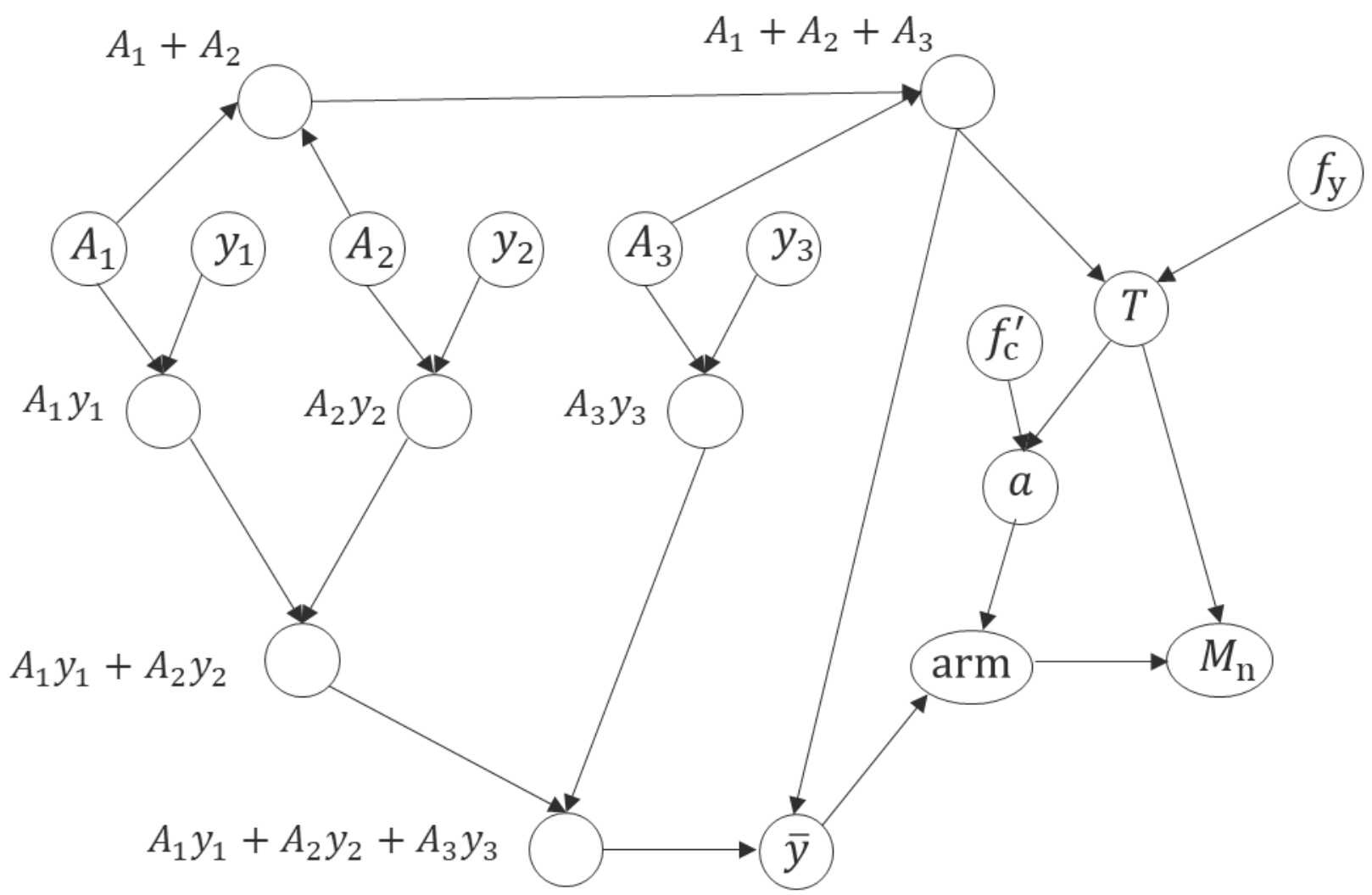

Table B1. CPT size for completely unraveled BN example.

\begin{tabular}{|l|c|c|}
\hline \multicolumn{1}{|c|}{ Group of nodes } & Number of nodes & CPT size for each node \\
\hline Inputs & $2 n+2$ & $d$ \\
\hline Computation of $A_{\text {total }}$ & $n-1$ & $d^{3}$ \\
\hline Computation of $S$ & $2 n-1$ & $d^{3}$ \\
\hline Computation of $M_{\mathrm{n}}$ & 5 & $d^{3}$ \\
\hline
\end{tabular}

\section{Summary}

Although motivated by issues particular to the BN shown in Figure B1, the techniques discussed in this appendix can be applied to any BN. These 
techniques are useful when a BN has a node with a large number of parent nodes. The dimensionality of the node's CPT is proportional to the number of its parents. This increases the memory requirements and, if the CPT is constructed by random sampling, also increases the computation time. Variable reduction is well-suited for a BN that has a large number of input variables, $x_{i}$, that are used to calculate some intermediate result, $f(\boldsymbol{x})$. However, variable reduction requires that the distribution of $f(\boldsymbol{x})$ can be expressed either in closed form or via approximation. In practice, therefore, variable reduction is limited to cases in which $f(\boldsymbol{x})$ is a simple function. Network unraveling is simple and straightforward (if slightly tedious) to apply, but requires the determination of good discretizations for all of the intermediate nodes that are created.

The programs developed in this work currently use variable reduction to achieve reasonably fast run times for analysis of sections and single girders. For an RC section, generating the $\mathrm{BN}$, compiling the $\mathrm{BN}$, and determining the probability of failure typically takes $0.3-0.4 \mathrm{sec}$. For a girder analysis, a significant amount of time is actually spent on moving load calculations. A girder analysis with eight segments and a live load consisting of a moving point load takes roughly $1.1 \mathrm{sec}$, of which about 1.0 sec is used for moving load calculations. If the automated HL-93 live load option is selected, the analysis takes roughly $7.5 \mathrm{sec}$, of which about $7.4 \mathrm{sec}$ is used for moving load calculations. The girder in these examples was 642 in. long, and the moving load calculations used a step size of $1 \mathrm{in}$. to "march" the load(s) across the girder. An increased step size can be used to achieve faster analysis times. 


\section{Appendix C: Example Reliability Analysis}

This appendix provides brief examples of the Bridge Reliability and Girder Condition prototype programs. First, the Bridge Reliability program is used to create a model of an RC girder for reliability analysis at a section. Second, the Girder Condition program is used to create a "map" or list of defects and apply it to the girder model from the first step.

\section{Creating a reinforced concrete girder model}

To begin, create a new model by selecting File > New Model... or pressing Ctrl $+\mathrm{N}$. A dialog (Figure $\mathrm{C} 1$ ) pops up prompting the user to select the girder type. The default (and only type currently supported) is "Reinforced Concrete." Select OK to continue.

Figure C1. New Model dialog.

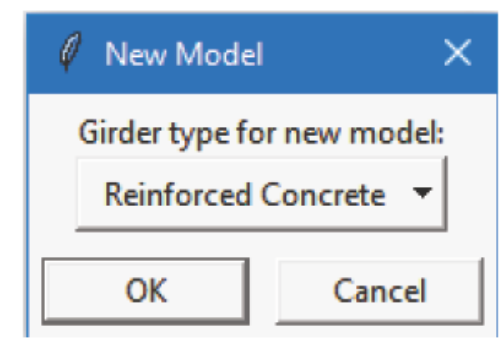

The model is populated with default values from the template (rc_default.xml), as shown in Figure C2. The specifics of this default template can easily be changed.

The interface (Figure C2) is organized into a number of panels. At the top, the Model information panel provides fields for metadata related to the model. These fields are optional and are intended to help document the model. These fields are not used in the analysis. The design type (in this case, "reinforcedConcrete") is shown and cannot be changed; it is for information only.

The Girder properties panel contains fields for the input of the girder parameters described in Section 3.3. Some variables (bearing-tobearing length, height, and width) are assumed to be deterministic and have only fields for a nominal value. The other variables have fields for input of the nominal value, bias, and COV. The number of bins with 
which to discretize the CPT can also be specified. The discretization will span a given number (\# st devs) of standard deviations above and below the mean of the variable. Note that Netica will automatically extend the first or last bin of the discretization as needed during the analysis if a value falls outside the current discretization.

The Load panel allows the choice of manually entering the moment load effect or letting the program automatically calculate the maximum moment load effect caused by the HL-93.

The Limit state discretization panel provides control over the discretization of the nodes for flexural capacity $\left(M_{\mathrm{n}}\right)$ and flexure limit state $\left(g_{\mathrm{M}}\right)$. Because these variables do not have means and standard deviations that are known a priori (and their distributions are not expected to be normal), the discretization is determined based on a minimum value, maximum value, and number of bins. Again, Netica will automatically extend the first or last bin of the discretization as needed if a value falls outside the current discretization. 
Figure C2. Default reinforced concrete girder model created from template.

\begin{tabular}{|c|c|c|c|c|c|}
\hline \multicolumn{4}{|l|}{ Untitled - Bridge Reliability } & - & $\times$ \\
\hline \multirow{2}{*}{\multicolumn{6}{|c|}{$\begin{array}{l}\text { File Edit View Help } \\
\text { Model information }\end{array}$}} \\
\hline & \multirow{2}{*}{\multicolumn{5}{|c|}{ Default reinforced concrete bridge }} \\
\hline Name & & & & & \\
\hline Description & \multicolumn{5}{|c|}{ Calculate the Probability of Failure of the main girder } \\
\hline \multicolumn{6}{|l|}{ NBIS } \\
\hline Number of spans & \multicolumn{5}{|l|}{1} \\
\hline & \multicolumn{5}{|c|}{ reinforcedConcrete } \\
\hline \multicolumn{6}{|l|}{-Girder properties- } \\
\hline Variable & Nominal & Bias & $\mathrm{COV}$ & \# bins & \# st devs \\
\hline Concrete compressive strength (ksi) & 3.5 & 1.1 & 0.18 & 5 & 3 \\
\hline Rebar yield strength (ksi) & 33.0 & 1.13 & 0.12 & 5 & 3 \\
\hline Moment load effect (kip-in.) & 40200.0 & 1.1 & 0.18 & 5 & 3 \\
\hline Bearing-to-bearing length (in.) & 642.0 & & & & \\
\hline Height (in.) & 83.0 & & & & \\
\hline Width (in.) & 28.0 & & & & \\
\hline \multicolumn{6}{|l|}{ Load } \\
\hline \multicolumn{6}{|l|}{ Limit state discretization- } \\
\hline Variable & Minimum & Maximum & \# bins & & \\
\hline Flexural capacity & 45000 & 90000 & 7 & & \\
\hline Flexure limit state & -1000 & 60000 & 7 & & \\
\hline \begin{tabular}{|l|l} 
Edit rebar layers... & Edit condition... \\
\end{tabular} & Run analysis & & & & \\
\hline
\end{tabular}

The visibility of the distribution details can be toggled by View >

Distribution details on/off or by pressing the keyboard shortcut Ctrl + D. When details are hidden, only the nominal value fields are shown (Figure 12). The Limit state discretization panel is also hidden. 
Figure C3. Model with distribution details hidden.

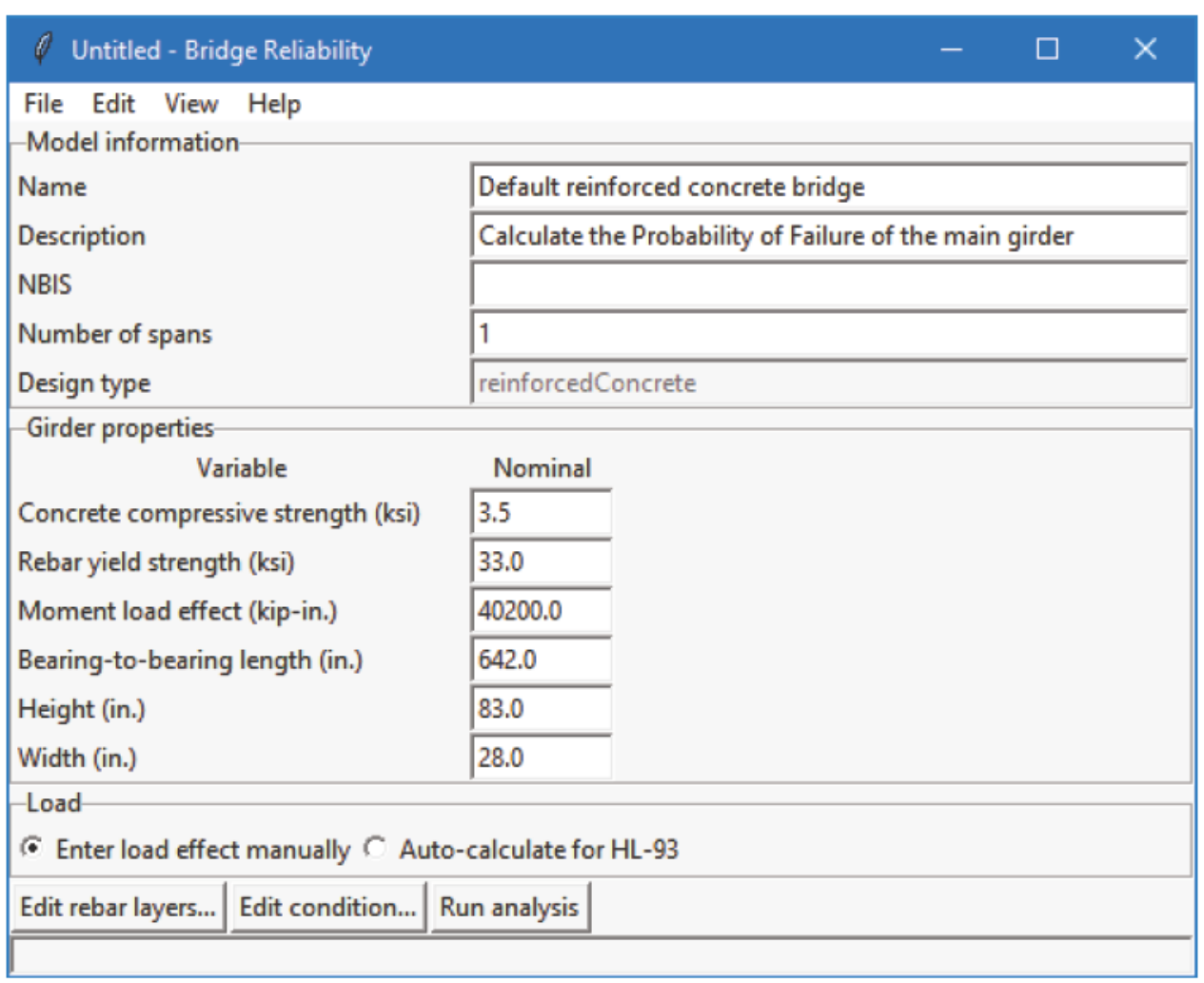

Click Edit rebar layers... to add or change layers of rebar. The "Rebar Layers" dialog box is shown in Figure C4. Inputs are given for each layer of rebar, not for individual bars. For each layer, enter a line consisting of the height of the layer's centroid above the bottom of the girder (in.), a comma, and the area of the layer (in. ${ }^{2}$ ). Spaces can also be used in addition to the comma. Spaces between numbers and commas are ignored; spaces are not allowed in the middle of numbers. 
Figure C4. Rebar layer editing.

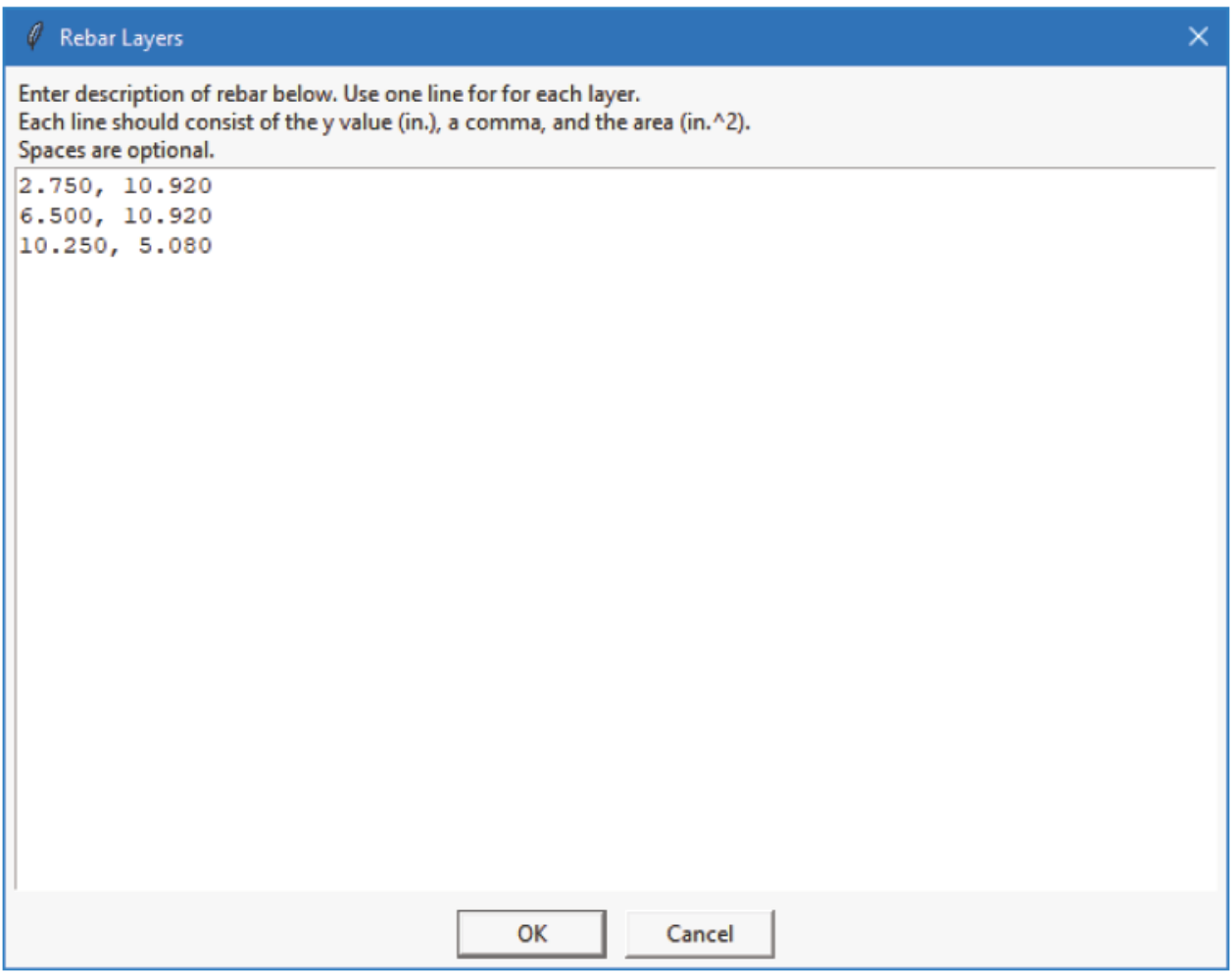

Click Edit condition... to enter defect findings for the girder at the section to be analyzed. The resulting dialog box allows ratings for seven defect types to be input by using drop-down menus, as shown in Figure C5(a). The full set of defects used for the example analysis is shown in Figure C5(b). 
Figure C5. Reinforced concrete girder condition editing.

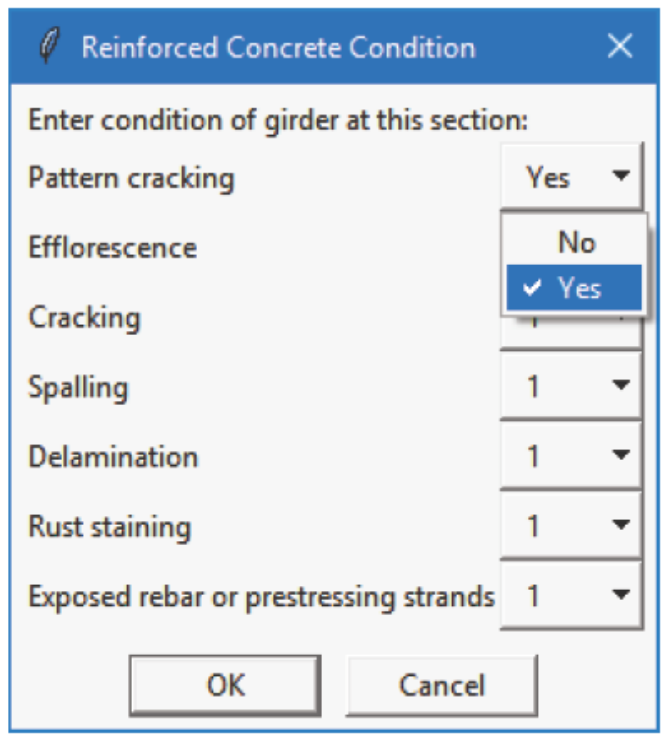

a. Example of entering a condition finding by using the drop-down menu.

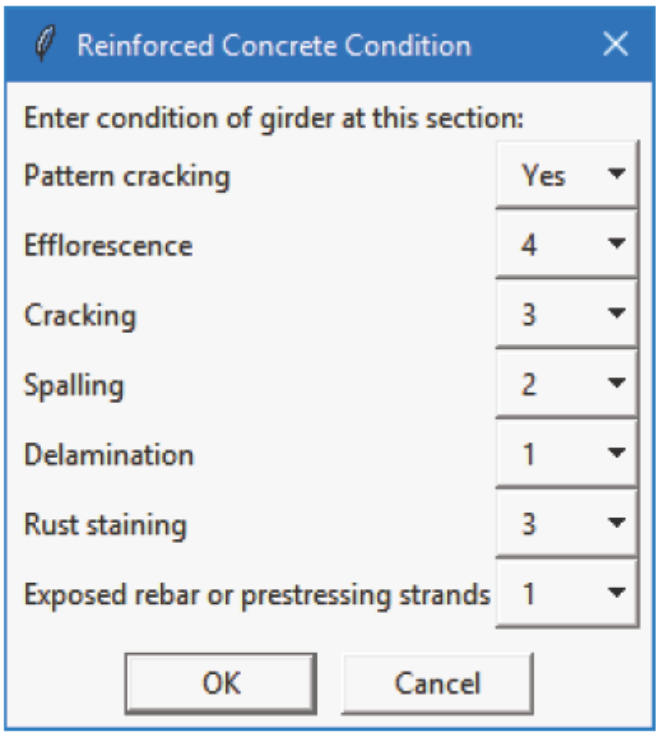

b. Complete condition findings for example analysis.

\section{Running a sectional reliability analysis}

To run an analysis, click Run analysis at the bottom of the window, select File > Run analysis, or press F5. Note that you must save the model file before running an analysis. If you try to run an analysis before saving, the program will notify you (Figure C6) and then provide a standard "Save File" dialog so you can save the file (Figure C7). After saving, the analysis will run; results are shown in Figure C8. With the defects entered in Figure C5(b), the estimated probability of failure is 6.73\%. For comparison, without defects (all fields in Figure C5 set to "No" or 1), the estimated probability of failure is $2.64 \%$ (Figure 18 ).

Figure C6. Attempting to run an analysis with an unsaved file.

\section{Bridge Reliability}

-

You must save the file before running an analysis. 
Figure C7. “Save File” dialog.

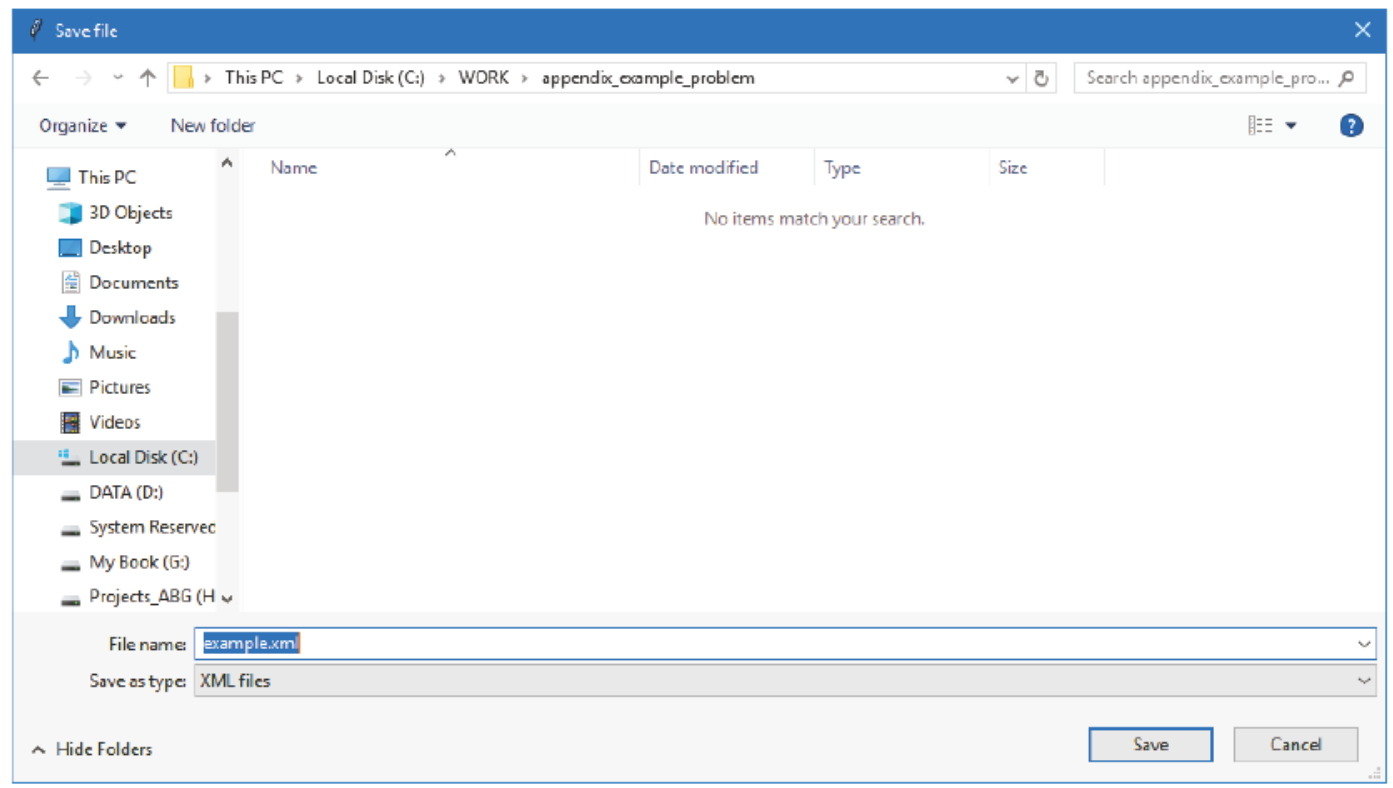

Figure C8. Results of analysis for an RC girder with defects.

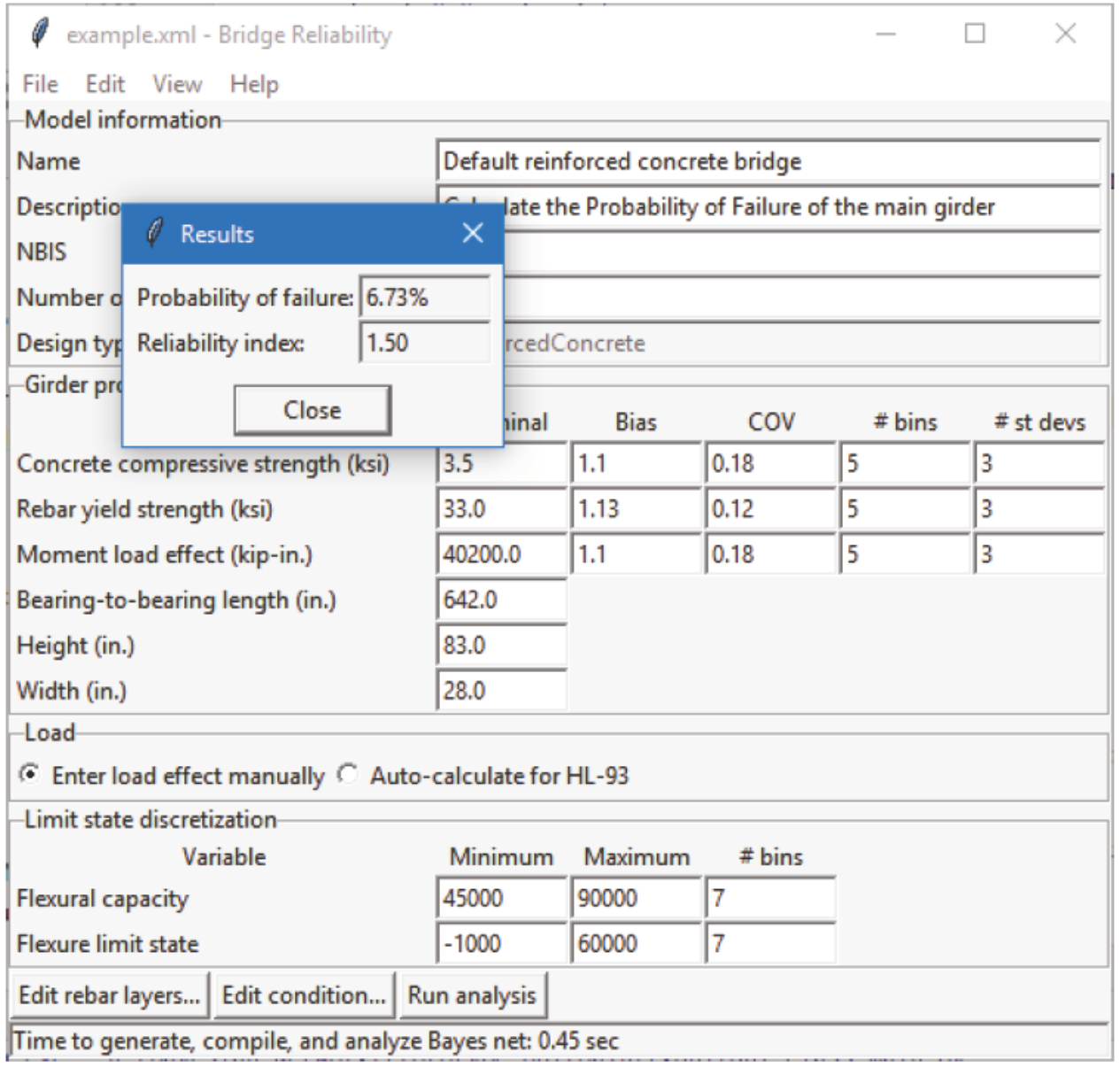


Figure C9. Results of analysis for an RC girder without defects.

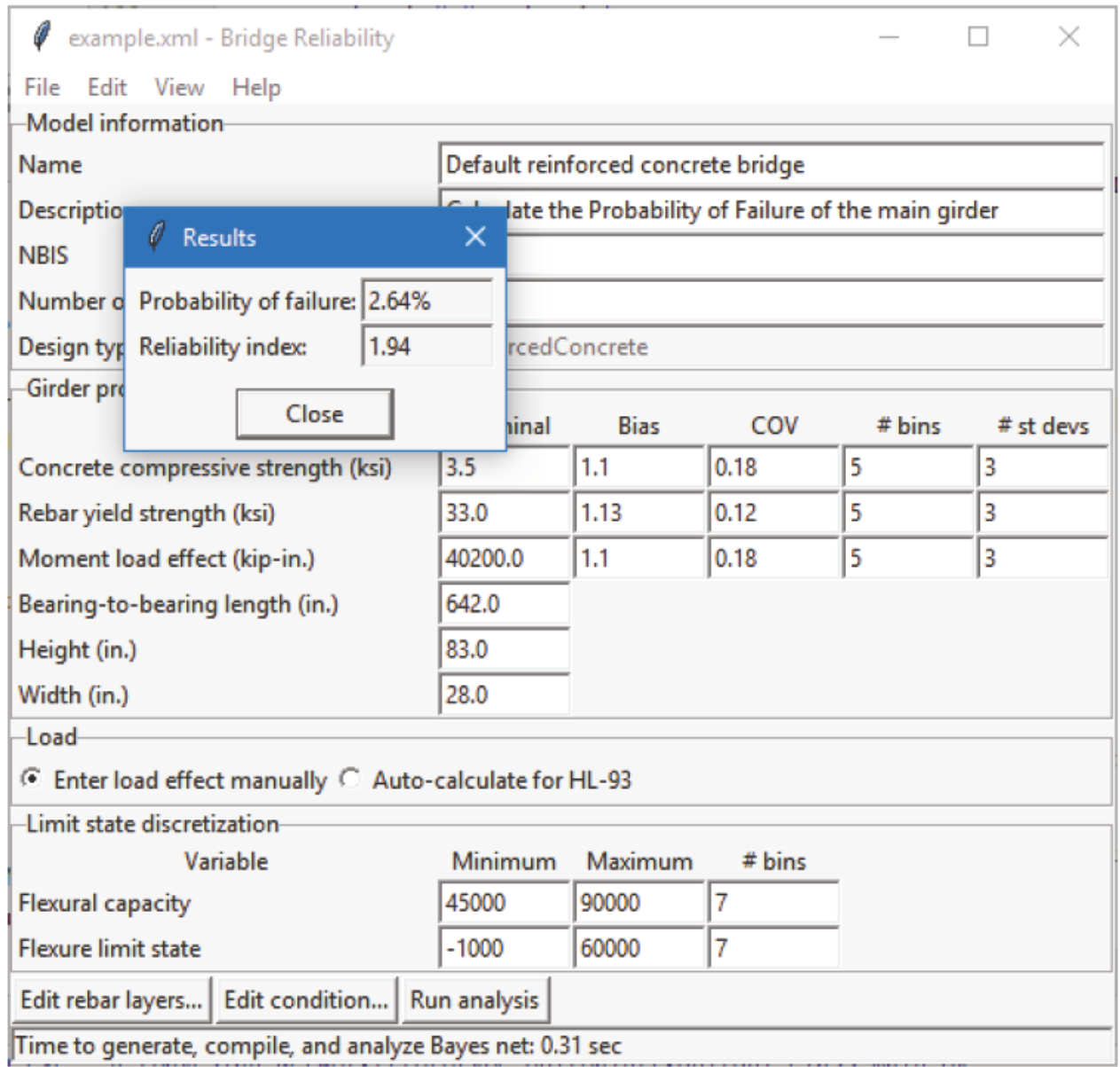

\section{Creating a defect "map" for a girder}

The Girder Condition program is primarily designed to create lists, or "maps," of defects for RC girders. To start entering defects, click Add finding... at the bottom of the window. A "Finding Entry" dialog pops up, as shown in Figure C10. Figure C11 shows the dialog box without the dropdown menu. The defect type, defect rating, and defect start and stop locations can be entered. For the example of pattern cracking, the defect rating field is disabled (grayed out); pattern cracking is treated as a binary finding (either pattern cracking is present or it is not). If a user is entering a finding for pattern cracking, that finding is obviously going to be that pattern cracking is present. For the other defect types, the defect rating is from 1 to 4 with 4 being the most severe. For the example, four defects will be entered. The result is shown in Figure C12. 
Figure 7C10. Girder Condition program showing “Finding Entry” dialog box.

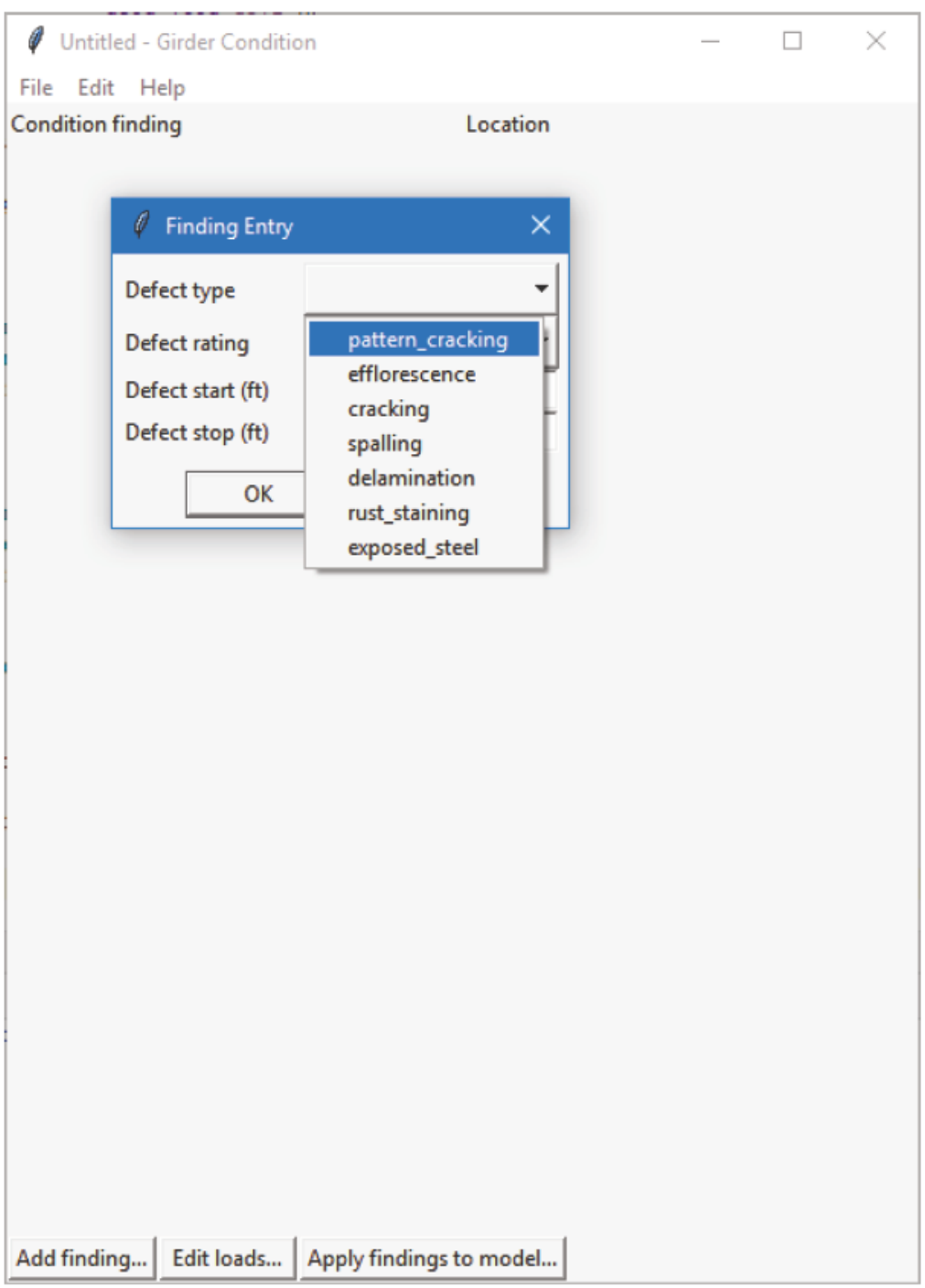

Figure C11. Defect start and stop locations.

\begin{tabular}{|c|c|c|}
\hline \multicolumn{2}{|l|}{ Finding Entry } & $x$ \\
\hline Defect type & pattern_cracking & $\checkmark$ \\
\hline Defect rating & 1 & 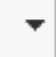 \\
\hline Defect start (ft) & 20 & \\
\hline Defect stop (ft) & 27 & \\
\hline OK & Cancel & \\
\hline
\end{tabular}


Figure C12. Defects for example analysis.

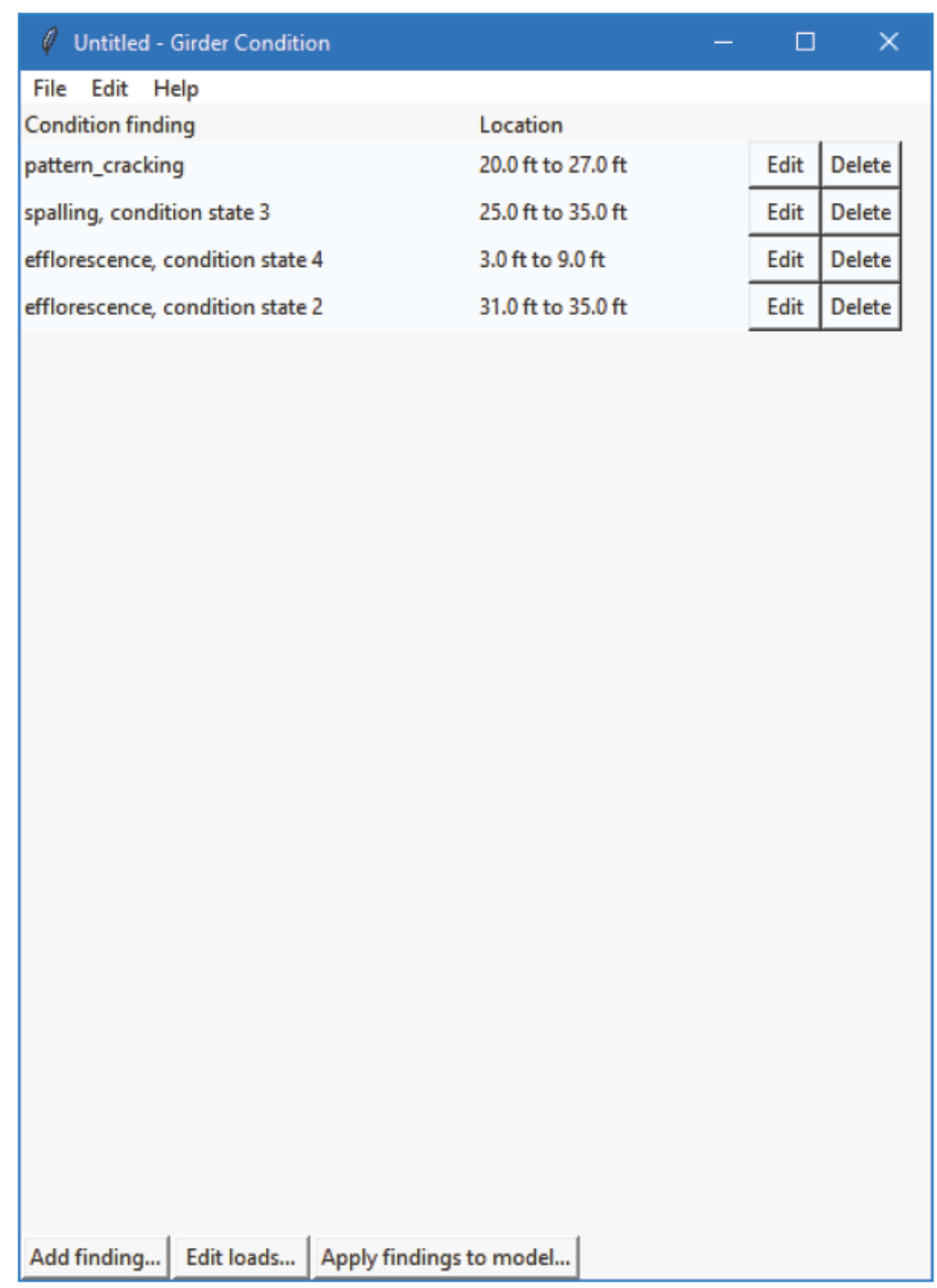

Any of the defect findings can be edited by clicking the Edit button to the right of the finding description. Editing brings back the same "Finding Entry" dialog box that was used to create the defect finding. Any of the inputs can be changed, including the defect type. To delete a defect finding, click the Delete button to the right of the finding description.

Save the findings by selecting File > Save findings or by pressing Ctrl + S. Call the file "defects.txt."

\section{Defining load case for whole girder analysis}

Click the Edit loads... button at the bottom of the window to enter (or change) the loads applied to the girder during the analysis. The resulting 
dialog box is shown in Figure 22. Currently, the options are fairly simple. A uniformly distributed dead load can be applied. For live load, either the HL-93 or a moving point load with a user-specified magnitude can be used. Loads can be saved by selecting File $>$ Save load case as... $(\mathrm{Ctrl}+\mathrm{L})$. An existing load case can be opened by selecting File > Open load case $(\mathrm{Ctrl}+\mathrm{Shift}+\mathrm{O})$. Loading and saving load cases is for convenience; the load case does not need to be saved to a file to perform an analysis. The loads currently in memory, whether manually entered in the dialog box or opened from a file, are used for analysis.

Figure C13. “Girder Loads" dialog box.

\begin{tabular}{l} 
Girder Loads \\
\hline Dead load \\
Total dead load (k/in.) $\quad \times$ \\
Live load \\
$\subset$ Auto-calculate for HL-93 \\
C Moving point load (kips) \\
$\qquad$\begin{tabular}{|c|}
250 \\
\hline OK
\end{tabular} \\
\hline
\end{tabular}

\section{Applying defects to a girder}

Click the Apply findings to model... button at the bottom of the window to analyze the reliability of a girder with the defect map. A dialog (Figure C14) opens to allow a girder model to be opened. For the example, select the RC girder model that was previously created with the Bridge Reliability program. The analysis will then be run. When the analysis concludes, a dialog box will provide summary information about the number of segments used, the time required, and the output files that were generated (Figure C15). Detailed information and diagnostics are also printed to the console window, a portion of which is reproduced below. Some lines have been omitted for brevity, and these are indicated by an italicized comment on what was omitted (... like this ...). The probability of girder failure, assuming dependent failure events, is $7.99 \%$.

Current Bayes Net file found, using it ...

Note: Using custom moment envelope defined by 250.0-kip moving point load 


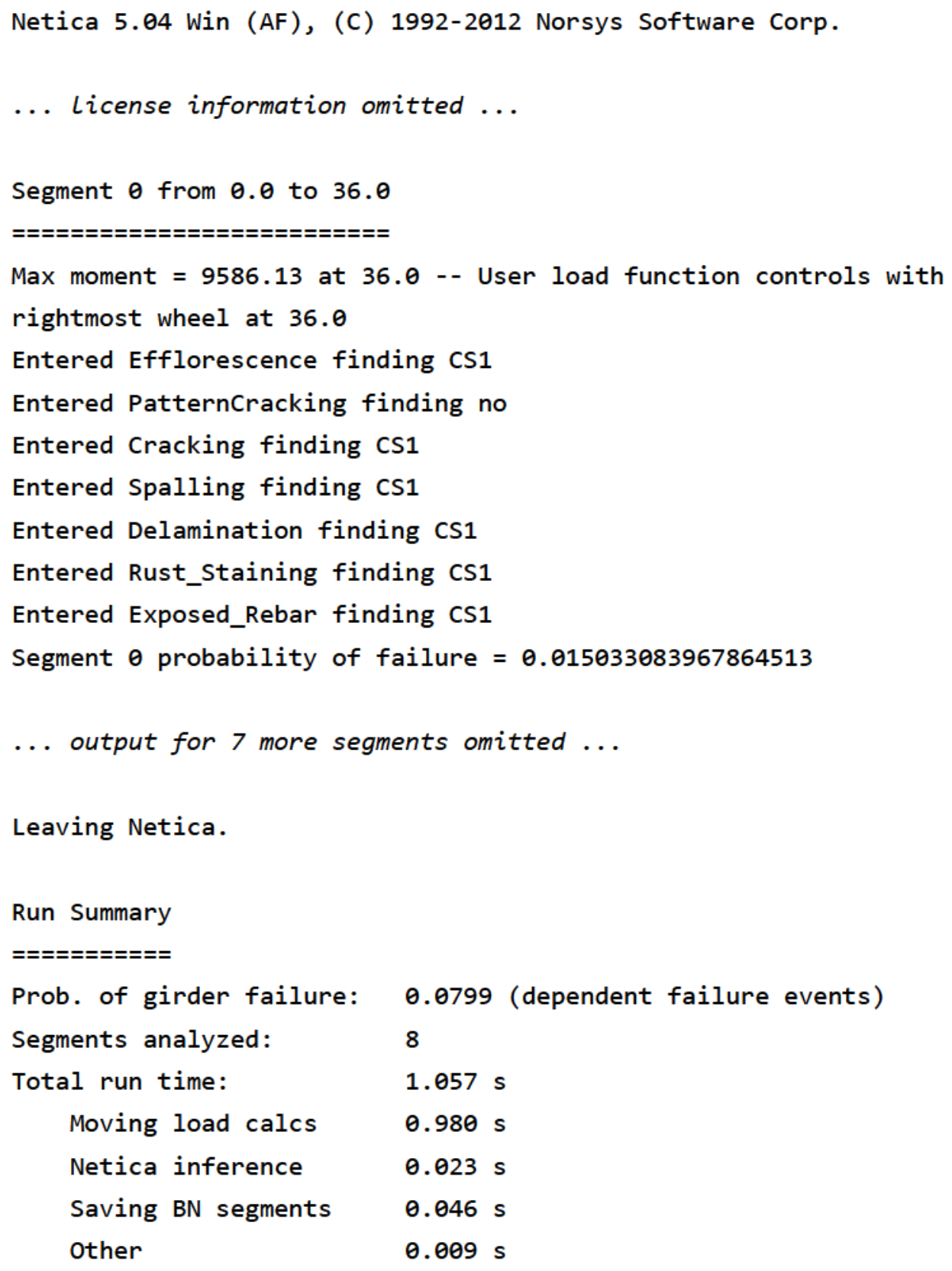


Figure C14. Select the RC girder model for the example analysis.

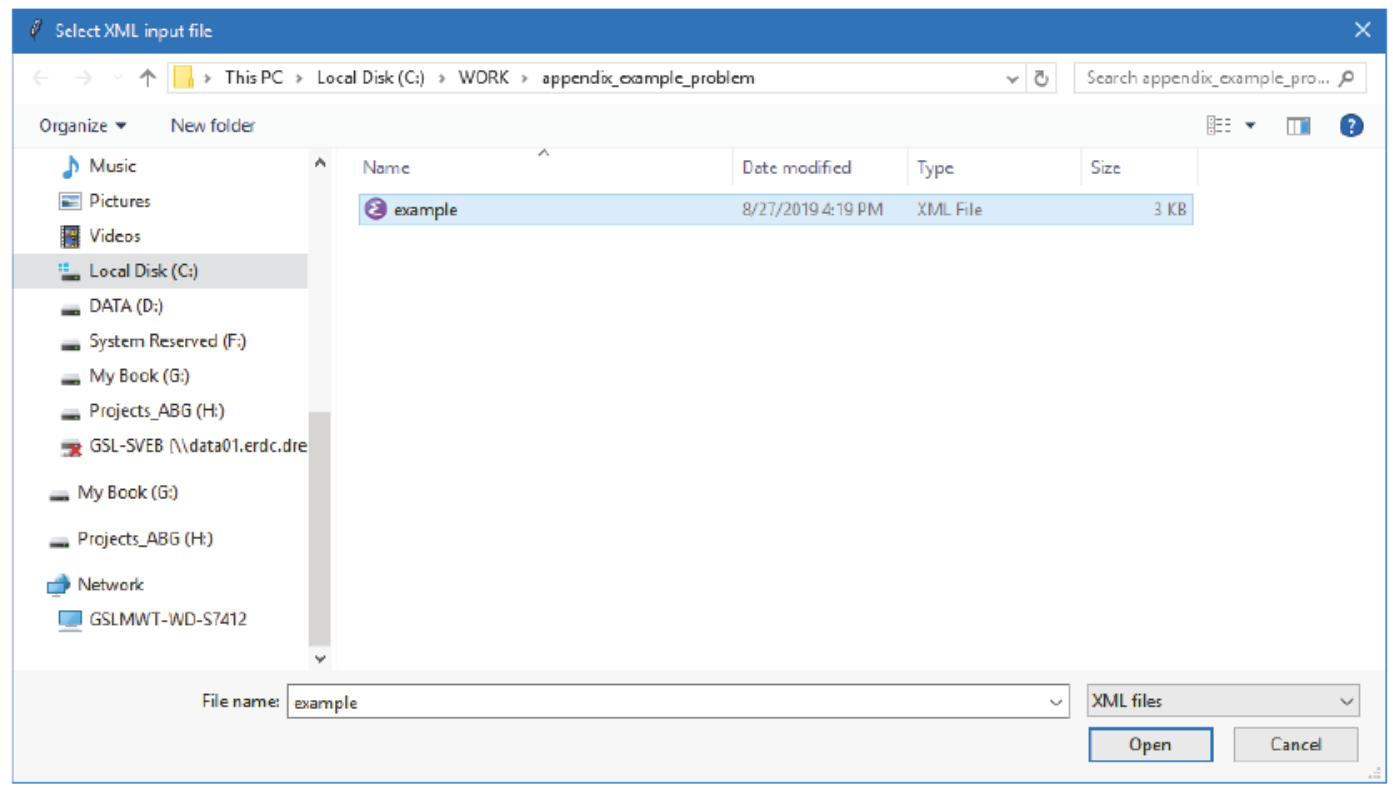

Figure $8 \mathrm{C} 15$. Analysis summary information.

\section{Analysis Complete!}

Analyzed 8 segments in 1.057 seconds.

BNs for each segment are saved as

C:/WORK/appendix_example_problem/example_seg0.neta through

C:/WORK/appendix_example_problem/example_seg7.neta.

A visualization of the girder results is saved in

C:/WORK/appendix_example_problem/example.vtk.

\section{OK}

\section{Visualizing results}

For easy viewing of results, "Girder Condition" generates a VTK file that can be read by the open-source visualization program ParaView (Ayachit 2018). ParaView can be run on Windows, Linux, or macOS.

Open the file "example.vtk" in ParaView (File > Open... or Ctrl + O). Be sure to click "Apply" to tell ParaView to load the data from the file into memory (see Figure C16). You will also need to change the representation from "Outline" to "Surface With Edges." After completing these two 
actions, a rendering of the girder will be shown. When a file is first opened in ParaView, the "Solid Color" variable is plotted, which shows the geometry and does not take long to render. A number of other variables can be selected from (see Figure C17).

The results in the VTK file are presented as a simple 3-D model of a girder. The view in ParaView can be manipulated with the mouse as follows:

- Rotate view - click and hold left mouse button

- Pan - click and hold middle mouse button

- Zoom - click and hold right mouse button

Complete details on using ParaView can be found in the User's Guide (Ayachit 2018).

Figure C16. ParaView visualization setup.

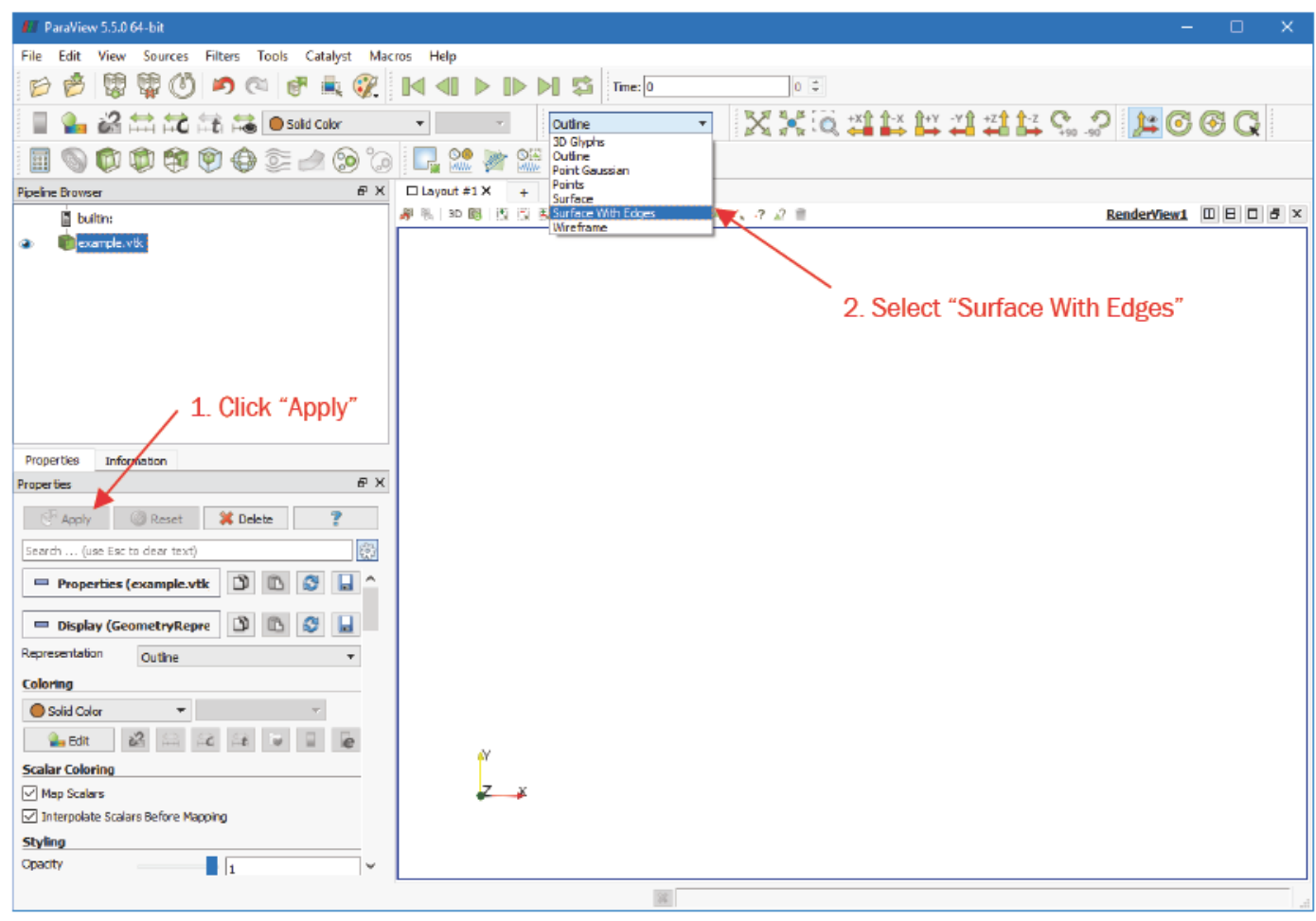


Figure C17. Variables available to visualize.

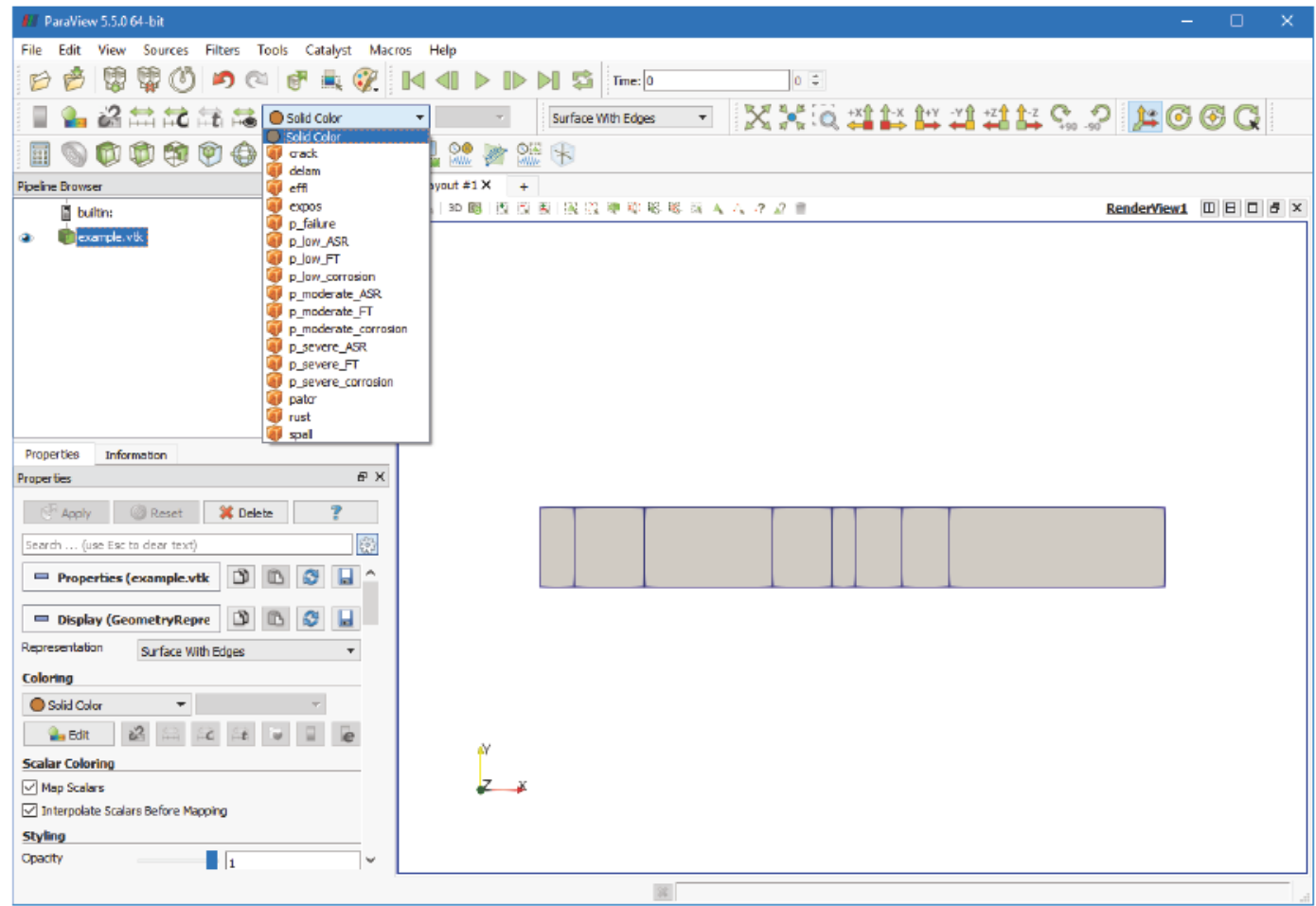

The inputs for defect location and severity can be visualized, as shown in Figures C18 through C20. Note that the girder has been segmented as needed to deal with overlapping defect regions. The VTK file also contains a number of probabilities output from the model. The variable p_failure is the probability of failure of a segment determined by reliability analysis at a section. There is also a series of variables that gives the inferred probability of having a given deterioration mechanism and severity in a segment. For example, p_low_ASR is the probability of having ASR with low severity. For each segment, p_low_ASR, p_moderate_ASR, and p_severe_ASR sum to 1 . The probability of failure for each girder segment is shown in Figure C21. The highest probability of failure is for the fifth segment from the left, which also has the highest probability of moderate ASR (Figure C22). 
Figure C18. Rendering of pattern cracking location.

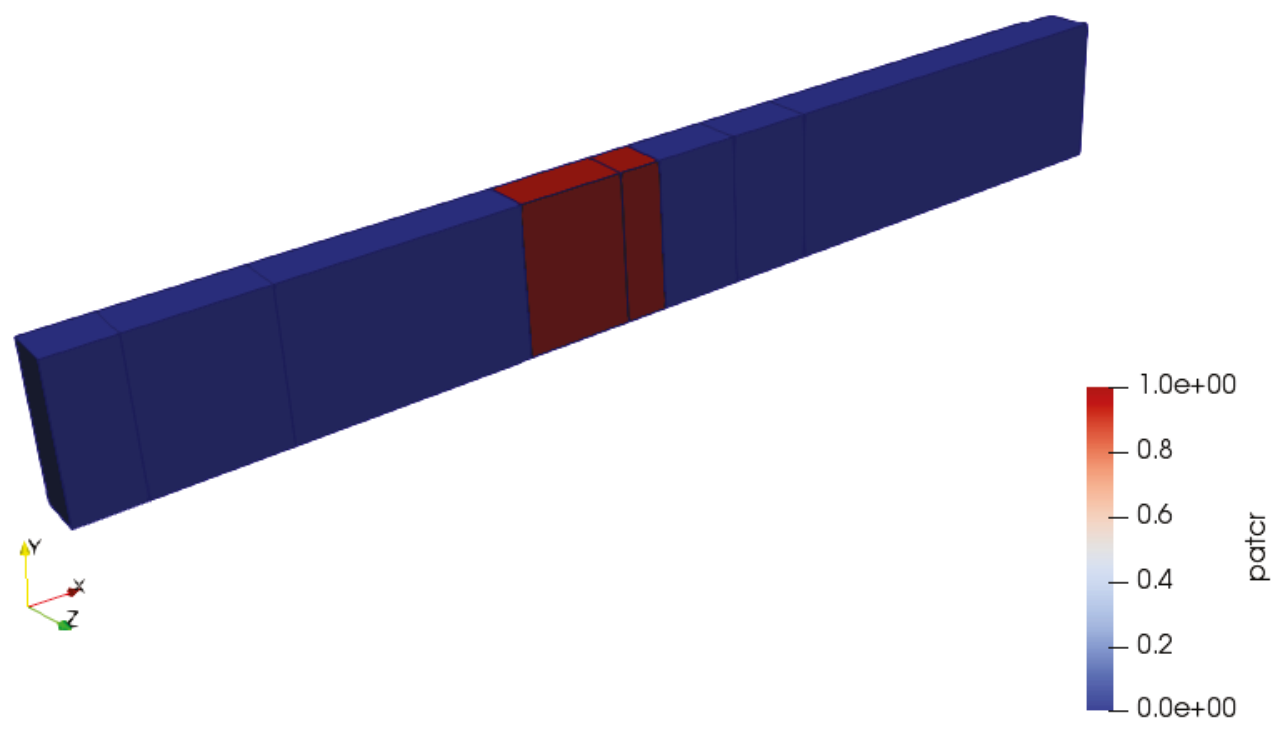




$$
\text { 三 }
$$


Figure C21. Rendering of probability of failure for girder segments.

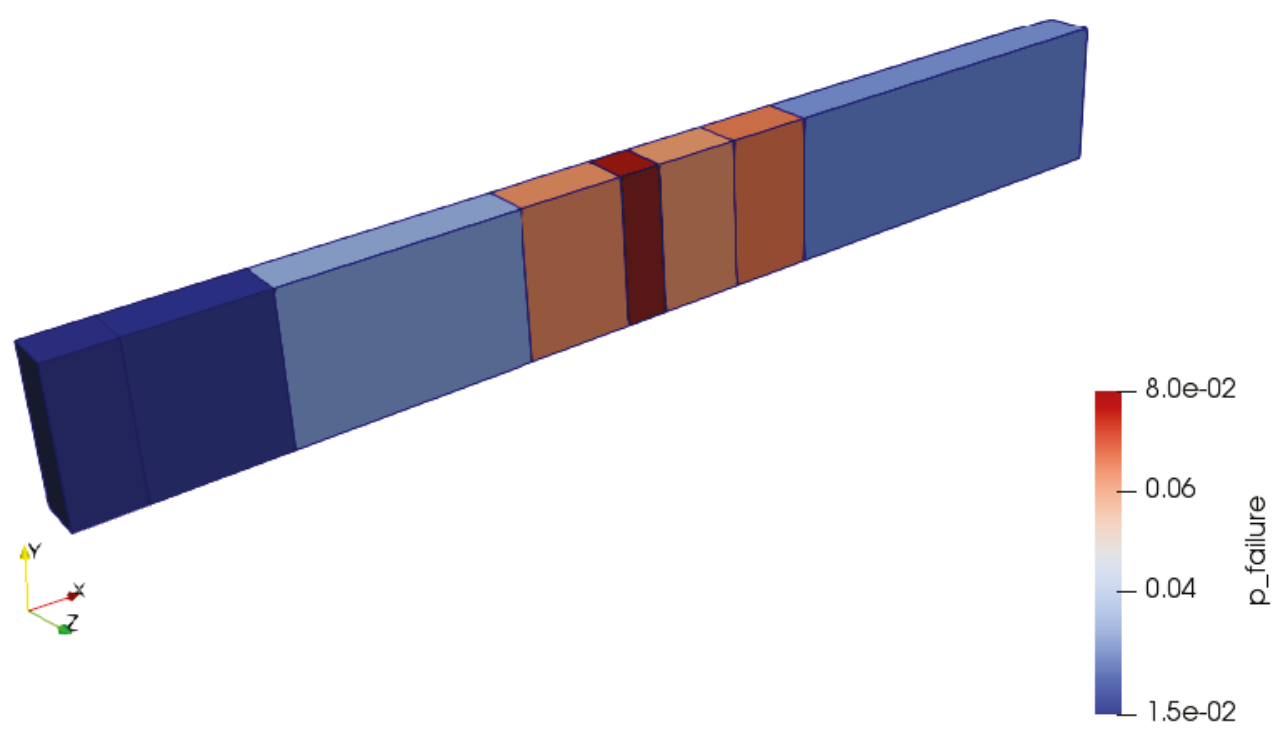


Figure C22. Rendering of probability of moderate ASR for girder segments.

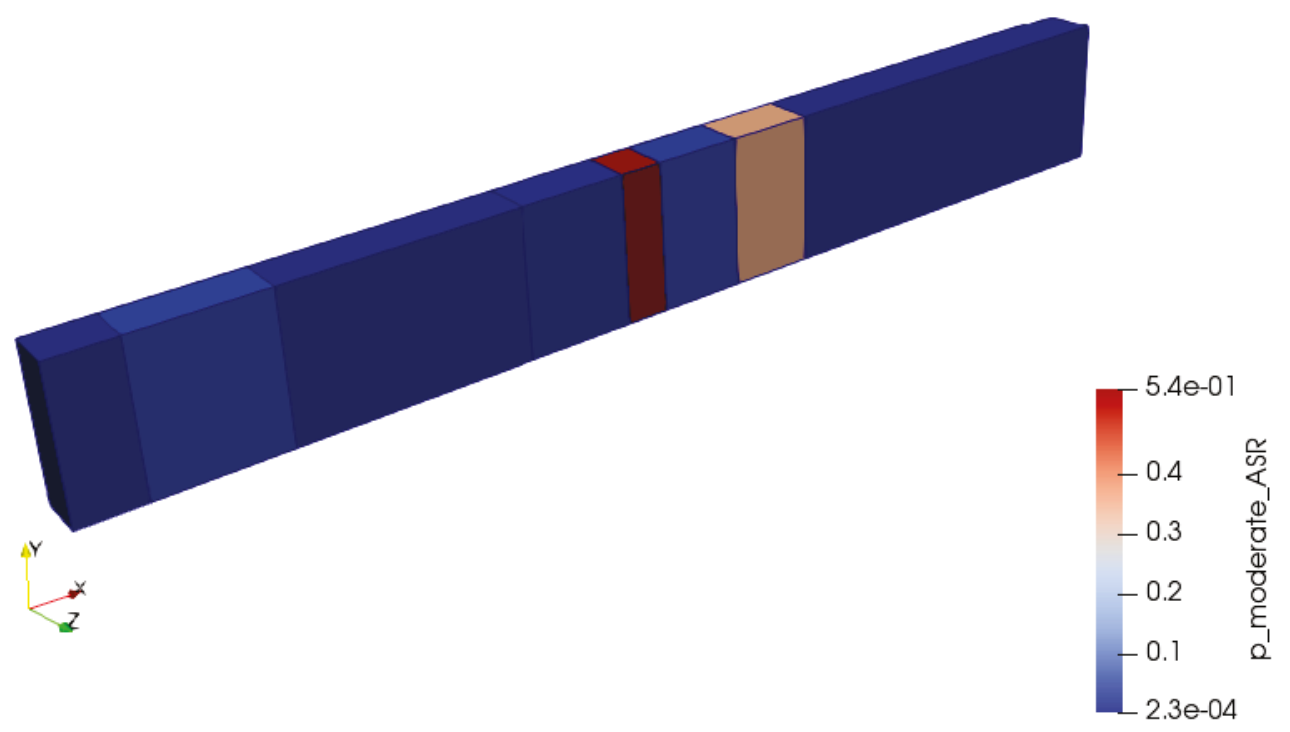




\section{Unit Conversion Factors}

\begin{tabular}{|l|c|l|}
\hline Multiply & By & To Obtain \\
\hline degrees Fahrenheit & $(\mathrm{F}-32) / 1.8$ & degrees Celsius \\
\hline feet & 0.3048 & meters \\
\hline inches & 0.0254 & meters \\
\hline pounds (force) & 4.448222 & newtons \\
\hline pounds (force) per square inch & 6.894757 & kilopascals \\
\hline pounds (mass) & 0.45359237 & kilograms \\
\hline
\end{tabular}




\section{Acronyms and Abbreviations}

$\begin{array}{ll}\text { Term } & \text { Definition } \\ \text { ASR } & \text { Application Programming Interface } \\ \text { BN } & \text { Alkali-Silica Reaction } \\ \text { COV } & \text { Coefficient of Variation } \\ \text { CPT } & \text { Conditional Probability Tables } \\ \text { FOSM } & \text { First Order, Second Moment } \\ \text { FT } & \text { Freeze-Thaw } \\ \text { GUI } & \text { Graphical User Interface } \\ \text { MBEI } & \text { Manual for Bridge Element Inspection } \\ \text { RC } & \text { Reinforced Concrete }\end{array}$




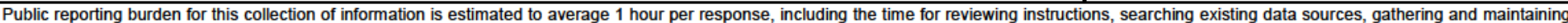

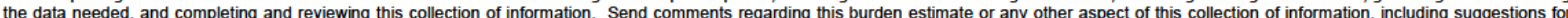

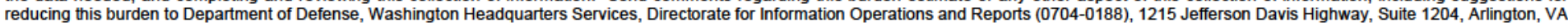

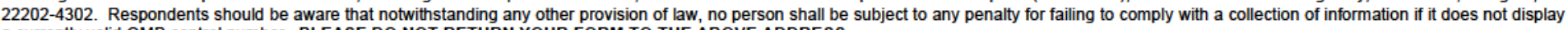
a currently valid OMB control number. PLEASE DO NOT RETURN YOUR FORM TO THE ABOVE ADDRESS.
1. REPORT DATE (DD-MM-YYYY) 2. REPORT TYPE
3. DATES COVERED (From - To)

February 2021 Final

\section{TITLE AND SUBTITLE}

Estimating Bridge Reliability by Using Bayesian Networks

5a. CONTRACT NUMBER

5b. GRANT NUMBER

5c. PROGRAM ELEMENT NUMBER

\section{AUTHOR(S)}

Andrew B. Groeneveld, Stephanie G. Wood, Edgardo Ruiz, and Jeffery M. Roberts

\section{5d. PROJECT NUMBER \\ 476923}

5e. TASK NUMBER

5f. WORK UNIT NUMBER

\section{PERFORMING ORGANIZATION NAME(S) AND ADDRESS(ES)}

Geotechnical and Structures Laboratory

U.S. Army Engineer Research and Development Center

3909 Halls Ferry Road

Vicksburg, MS 39180-6199

9. SPONSORING / MONITORING AGENCY NAME(S) AND ADDRESS(ES)

U.S. Army Corps of Engineers

Washington, DC 20314-1000

Headquarters, Installation Management Command

Fort Sam Houston, TX 78234-1223

\section{DISTRIBUTION / AVAILABILITY STATEMENT}

Approved for public release; distribution is unlimited.

\section{SUPPLEMENTARY NOTES}

The Army Dams and Transportation Infrastructure Program (ADTIP) from the Installation Management Command (IMCOM) provided supplemental funding under Project 154349, "Army Dams and Transportation Infrastructure Program."

\section{ABSTRACT}

As part of an inspection, bridge inspectors assign condition ratings to the main components of a bridge's structural system and identify any defects that they observe. Condition ratings are necessarily somewhat subjective, as they are influenced by the experience of the inspectors. In the current work, procedures were developed for making inferences on the reliability of reinforced concrete girders with defects at both the cross section and the girder level. The Bayesian network (BN) tools constructed in this work use simple structural mechanics to model the capacity of girders. By using expert elicitation, defects observed during inspection are correlated with underlying deterioration mechanisms. By linking these deterioration mechanisms with reductions in mechanical properties, inferences on the reliability of a bridge can be made based on visual observation of defects. With more development, this BN tool can be used to compare conditions of bridges relative to one another and aid in the prioritization of repairs. However, an extensive survey of bridges affected by deterioration mechanisms is needed to confidently establish valid relationships between deterioration severity and mechanical properties.

\begin{tabular}{|c|c|c|c|c|c|}
\hline \multicolumn{2}{|c|}{ 15. SUBJECT TERMS } & ability & & \multicolumn{2}{|c|}{ Reliability (Engineering) - Statistical methods } \\
\hline \multicolumn{2}{|l|}{ Bridges } & erial defects & & \multicolumn{2}{|c|}{ Bridges-Maintenance and Repair } \\
\hline \multicolumn{2}{|c|}{ Bayesian networks } & d rating & & \multirow{2}{*}{\multicolumn{2}{|c|}{ Bridges--Inspection }} \\
\hline \multicolumn{2}{|c|}{ Bayesian statistical decision theory } & crete bridges- & and constructic & & \\
\hline \multicolumn{3}{|c|}{ 16. SECURITY CLASSIFICATION OF: } & 17. LIMITATION & 18. NUMBER & $\begin{array}{l}\text { 19a. NAME OF RESPONSIBLE } \\
\text { PERSON }\end{array}$ \\
\hline $\begin{array}{l}\text { a. REPORT } \\
\text { Unclassified }\end{array}$ & $\begin{array}{l}\text { b. ABSTRACT } \\
\text { Unclassified }\end{array}$ & $\begin{array}{l}\text { c. THIS PAGE } \\
\text { Unclassified }\end{array}$ & SAR & 67 & $\begin{array}{l}\text { 19b. TELEPHONE NUMBER (include } \\
\text { area code) }\end{array}$ \\
\hline
\end{tabular}

